\title{
La dimensión territorial en la frontera sur del Virreinato del Río de la Plata:las expediciones hacia las Salinas Grandes en la época tardocolonial
}

The territorial dimension of the southern frontier of the Viceroyalty of the Río de la Plata: the expeditions to the Salinas Grandes during the late colonial time

\section{Sabrina Lorena Vollweiler}

\section{(2) OpenEdition}

\section{Journals}

\section{Electronic version}

URL: http://journals.openedition.org/corpusarchivos/2608

DOI: 10.4000/corpusarchivos. 2608

ISSN: 1853-8037

\section{Publisher}

Diego Escolar

\section{Electronic reference}

Sabrina Lorena Vollweiler, « La dimensión territorial en la frontera sur del Virreinato del Río de la Plata: las expediciones hacia las Salinas Grandes en la época tardocolonial », Corpus [En línea], Vol. 8, No 2 | 2018, Publicado el 22 enero 2019, consultado el 20 abril 2019. URL : http://

journals.openedition.org/corpusarchivos/2608 ; DOI : 10.4000/corpusarchivos.2608

This text was automatically generated on 20 April 2019.

Licencia Creative Commons: Atribución-NoComercial 2.5 Argentina (CC BY-NC 2.5 AR) 


\section{La dimensión territorial en la} frontera sur del Virreinato del Río de la Plata:las expediciones hacia las Salinas Grandes en la época tardocolonial

The territorial dimension of the southern frontier of the Viceroyalty of the Río de la Plata: the expeditions to the Salinas Grandes during the late colonial time

Sabrina Lorena Vollweiler

\section{EDITOR'S NOTE}

Fecha de recepción del original: 10/09/2018

Fecha de aceptación para publicación: 10/11/2018

\section{Introducción: las expediciones hacia las salinas Grandes}

En el transcurso del siglo XVIII, la ciudad de Buenos Aires se abasteció de sal mediante la organización de expediciones hacia unas salinas localizadas en el actual departamento de Atreucó de la provincia de La Pampa en la actual República Argentina. Organizadas por el Cabildo de Buenos Aires, partían desde la guardia de Luján y se dirigían hacia la Laguna de la Sal, también conocida como Salinas Grandes. ${ }^{1}$ En este trabajo buscamos reflexionar en torno a las relaciones sociales entabladas durante esas expediciones, atendiendo a las negociaciones entre los grupos indígenas de la región y los representantes de la agencia 
colonial que periódicamente se acercaban a ella. Entre otras fuentes disponibles, presentaremos aquí parte de la documentación elaborada por Manuel Pinazo, ${ }^{2}$ conformada por tres diarios que relatan el día a día de las incursiones ejecutadas en los años 1786,1787 y 1788 y un documento elaborado en 1788 con el listado de los cautivos rescatados en el transcurso de esas tres expediciones consecutivas a su mando. ${ }^{3}$

2 Según Taruselli (2005-2006), el descubrimiento de las Salinas Grandes data del año 1668 y la ejecución de expediciones oficiales se produjo desde comienzos del siglo XVIII. La organización de esas incursiones estaba a cargo del Cabildo de Buenos Aires, que promulgaba un bando para convocar a los vecinos interesados en integrar la expedición y, además, costeaba la tropa de escolta conformada por milicianos con el objetivo de brindar seguridad a los integrantes de las comitivas y de controlar la empresa. ${ }^{4}$ Para cada expedición se designaba a un comandante con conocimientos sobre la campaña; en las de estos años el cargo recayó en Manuel Pinazo, un maestre de campo con una larga trayectoria en el área, retirado del servicio para ese entonces.

Durante el transcurso de la década de 1780, las relaciones interétnicas en la frontera sur de Buenos Aires se caracterizaron por un clima de relativa paz, luego de años de fluctuantes alianzas y conflictos entre funcionarios coloniales y caciques indígenas. ${ }^{5} \mathrm{En}$ 1786, año del primer viaje que analizamos aquí, la sal escaseaba y poseía un elevado precio ya que desde 1782 había sido imposible realizar los viajes planificados. Debido a esto, en 1786 se necesitaba asegurar el éxito de la expedición y decidieron nombrar a Manuel Pinazo comandante "no menos por sus largas antiguas experiencias, que por el buen nombre que entre los mismos hacendados y demás gentes que habitan en el campo ha tenido y conserva este sujeto". ${ }^{6}$ Las expediciones hacia las Salinas Grandes, además de ser utilizadas para la extracción de recursos económicos, proveían una oportunidad de conocimiento de la modalidad de circulación de los grupos indígenas y los caciques de la región (Nacuzzi 2013) y tenían también entre sus objetivos el rescate de personas que se encontraban cautivas en las tolderías indígenas. Por este motivo, los diarios y cartas mencionadas y el documento elaborado en 1788 por Manuel Pinazo ofrecen información sobre esos tópicos.

Los diarios de operaciones de estas incursiones hacia las Salinas Grandes daban cuenta de los acontecimientos cotidianos en el terreno, del estado de los caminos, de la disponibilidad de recursos para los expedicionarios, de las interacciones con caciques y grupos indígenas. Además, se generaba un intercambio de información por escrito generalmente cartas- sobre esos mismos ítems, sobre los preparativos, sobre diversas situaciones acaecidas durante su ejecución -que no siempre se consignaban en los diarios - , sobre las notificaciones e informes una vez finalizada la marcha, entre otras cuestiones. Se encuentran también documentos acerca de la planificación de cada comitiva, como la designación de un comandante, la convocatoria a los vecinos a participar con sus carretas, la adjudicación de una escolta para la protección de la caravana y la solicitud de víveres y armamentos entre otros insumos. ${ }^{7}$ Consideramos que toda esa documentación forma parte de una "serie de carácter dialógico" que contiene información complementaria (Nacuzzi 2018, p.209). Además, en este caso, los tres diarios de las expediciones de 1786, 1787 y 1788 fueron escritos por el mismo autor, lo cual implica una situación casi experimental que haría posible conocer con más detalle cómo un funcionario como Pinazo comprendía el territorio y cómo su presencia reiterada durante tres años consecutivos iba produciendo ciertas modificaciones en él. Esto, a su 
vez, nos permitirá vislumbrar la dinámica de las expediciones en ese momento en particular y también en una escala temporal más amplia.

5 En este trabajo adoptaremos una perspectiva que considera la dimensión territorial del espacio de las Salinas atendiendo a la conjunción del espacio geográfico y de las relaciones sociales entre los grupos indígenas y los funcionarios coloniales que sucedían en el transcurso de las expediciones de aprovisionamiento de sal. Seguiremos $-\mathrm{y}$ discutiremos- el planteo de Enrique (2015), quien sostiene que las Salinas Grandes y la guardia de Luján conformaron "nodos territoriales", parajes relevantes tanto para los grupos indígenas como para los funcionarios de la colonia. Desde ese marco, analizaremos la dimensión espacial y territorial de los parajes implicados en el trayecto de las expediciones, que pueden considerarse intermedios respecto de esos nodos, así como diversas interacciones que se desplegaban en la laguna de la Sal. A continuación describiremos brevemente las fuentes haciendo énfasis en los datos que podemos obtener al leerlas en conjunto, para luego discutir la problemática planteada.

\section{La expedición de 1786}

7 Como hemos mencionado, la serie de documentos aquí presentados comienza con un diario elaborado por Manuel Pinazo sobre la expedición del año 1786 (Transcripción $N^{\circ} 1$ ) en el que relata los sucesos acaecidos durante la ida y el regreso de la laguna de la Sal. ${ }^{8}$ Comienza en la frontera de Luján el $1^{\circ}$ de octubre de ese año -el día señalado por el bando publicado por el Cabildo- en el que Pinazo se presentó a esperar a las carretas que voluntariamente concurrirían a la expedición y a la tropa designada para escoltarla. Describe la cantidad de carretas, el orden en el que había emprendido la marcha y relata, día por día, los sucesos, los parajes por los que caminaban, las leguas recorridas y los caciques con los que interactuaban, entre otras cuestiones. El escrito se refiere tanto a la ida hacia la laguna de la Sal como al regreso desde la misma hacia la frontera de Luján, a la que arribaron el 28 de noviembre.

Además, existe otro diario sobre esta expedición publicado por Pedro de Angelis escrito por Pablo Zizur, un piloto de la Real Armada Española a quien por esos años se le encomendaron diversas expediciones de reconocimiento del territorio. ${ }^{9}$ Manuel Pinazo fue el comandante de la expedición, mientras que Pablo Zizur fue designado por el Cabildo para concurrir con el objetivo de "examinar con toda exactitud la laguna Grande en donde se acopia la sal necesaria para el abasto de esta ciudad con el justo e interesante fin de formar en las inmediaciones de dicha laguna una fortaleza", así como de una "población que ponga el paso libre a todos los moradores sin recelo de los riesgos e incursiones de los indios bárbaros". Para ese fin, debía realizar un mapa topográfico durante la ida hacia las Salinas y un diario en el regreso a la guardia de Luján ${ }^{10}$ [figura № 
1].

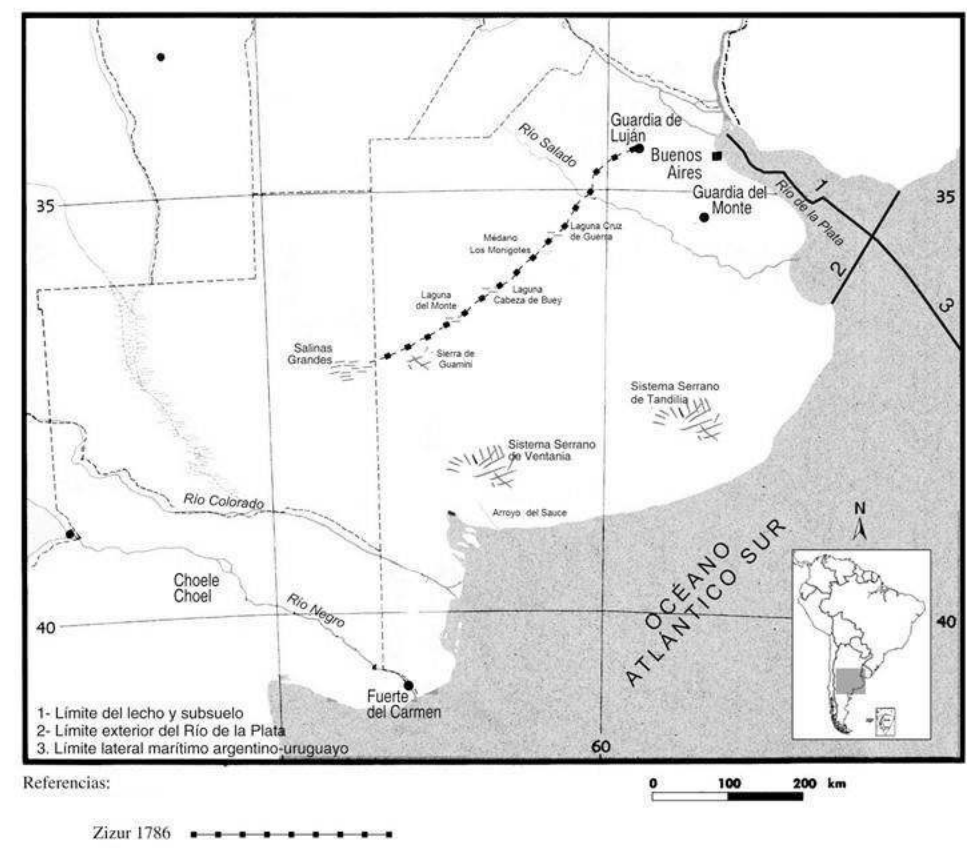

Figura $N^{0} 1$. Representación del recorrido realizado por Pablo Zizur en 1786. Adaptado de Martínez Sierra (1975) y Enrique (2016).

El diario de Zizur ${ }^{11}$ permite complementar el estudio de la dimensión espacial de las Salinas Grandes ya que comienza con una descripción de la laguna (su localización, forma, componentes del suelo y del terreno que la rodea), de las cañadas y manantiales que la circundan (el tipo de agua y su estacionalidad), la vegetación y el nivel del terreno aledaño. Luego de la descripción de las Salinas y sus alrededores relata el regreso hacia la guardia de Luján, donde detalla día por día los rumbos y las distancias recorridas, los relieves que se presentaban en el camino, la composición y calidad del terreno, los pastos y la disponibilidad de leña y agua. Al contrastar la información que brinda cada uno en su diario observamos discrepancias, ya que Manuel Pinazo estaba enfocado en el acopio de sal, en las negociaciones con los grupos indígenas y en los rescates de cautivos, mientras que Pablo Zizur debía relevar y registrar las lagunas y los territorios aledaños, en especial las Salinas. Entre sus tareas, Pinazo debería "auxiliar esta comisión [de Zizur] por todos los medios" como por ejemplo con la "escolta de gente" ${ }^{12}$ Por esto, en su diario dejó por escrito las decisiones que tomó como comandante de la expedición para cumplir con esas órdenes, por lo que su manuscrito nos permite conocer algunos pormenores que formaron parte del relevamiento realizado por Zizur pero que no fueron incluidos en el diario del piloto. Asimismo, en el diario elaborado por Zizur se describen aspectos del mismo viaje; en él se omiten las menciones a caciques y grupos indígenas ya que estaba centrado en otros aspectos. ${ }^{13} \mathrm{Si}$ bien ambos relatos detallan particularidades de la expedición realizada ese año, el escrito de Pinazo nos permite conocer las relaciones entre los funcionarios y los grupos indígenas en los diversos parajes recorridos durante ese viaje. 


\section{La expedición de 1787}

9 Al año siguiente se volvió a designar a Manuel Pinazo comandante de la expedición a Salinas a partir del nombramiento del año previo. ${ }^{14}$ Las instrucciones que recibió se centraron en la necesidad del abasto público, con énfasis en la decisión de realizar el viaje "sin hostilizar en la ocasión a los indios" por lo que se priorizaría la carga de la sal en esa oportunidad. Asimismo, se le ordenó "recoger de las manos de los infieles a los pobres cautivos" así como aprovechar para observar y relevar las situaciones tierra adentro con el objetivo de "invadirlos con oportunidad". ${ }^{15}$ El diario elaborado por Pinazo (Transcripción $\mathrm{N}^{\circ} 2$ ) nos permite conocer algunas de las relaciones establecidas en el territorio entre los funcionarios coloniales y los grupos indígenas. Al igual que el año anterior, Pinazo también detalló día por día las leguas recorridas, los parajes divisados, los caciques y grupos indígenas que se acercaron a la expedición a vender sus productos, la búsqueda de ganado por parte de las partidas así como aquellas situaciones particulares acontecidas en esa expedición. Por ejemplo, de regreso Pinazo se enteró, por medio de cacique Currutipay, de unos rumores sembrados entre los grupos indígenas por un peón -que había desertado a la ida- sobre la intención del comandante de "pasar a cuchillo todos los indios". También tomó conocimiento de un posible ataque de los tehuelches que no se efectivizó y lidió con un conflicto entre dos soldados blandengues y dos indígenas. Por último, le informaron que había un grupo de indígenas "convocados con el cacique Lorenzo para invadir en el Zanjón partido de la Magdalena" por lo que envió una carta al virrey para dar aviso de ese posible ataque. ${ }^{16}$

10 Entre la documentación que se generó con motivo de la expedición de ese año existe una extensa carta que también relata los sucesos del viaje pero en un orden diferente al del diario. Enviada el 23 de noviembre por Pinazo al marqués de Loreto desde un campo cercano a la Cabeza del Buey (a mitad del camino de regreso), se encuentra dividida en párrafos temáticos. Comienza con una mención al arribo a ese paraje con "felicidad", relata que habían "conservado una buena armonía" con los grupos indígenas y enumera los caciques y los familiares de ellos que habían concurrido a su campamento en el camino de ida y en la laguna de la Sal. Además del relato de los problemas que lo habían mantenido ocupado y del informe acerca de un inminente ataque a las guardias, Pinazo anunciaba también los rescates de cautivos que había logrado a pesar de las circunstancias desfavorables y del estado de sequía del campo. ${ }^{17}$ Creemos que la carta, enviada unos pocos días antes de la llegada a la guardia de Luján, de regreso de la expedición, fue un documento utilizado para anticipar la información sobre algunas situaciones conflictivas que daba cuenta de los motivos que habían guiado las decisiones del comandante. Podemos suponer que fue escrita durante la expedición, mientras que el diario posiblemente fue redactado una vez finalizada la misma, quizás a partir de anotaciones efectuadas durante el viaje.

\section{La expedición de 1788}

Conocemos la última incursión aquí analizada a partir de un tercer diario elaborado por el mismo autor de los años anteriores, junto con otros documentos producidos con el fin de organizar y ejecutar la expedición. En 1788 Pinazo había sido "nombrado comandante de la presente expedición a Salinas por el excelentísimo señor Marqués de Loreto virrey 
gobernador, y capitán general de estas provincias con igual confianza, que en los años anteriores". Esta pieza documental (Transcripción $N^{\circ}$ 3) también contiene información acerca de las relaciones entre los funcionarios y los caciques en los distintos parajes recorridos durante el viaje. Por ejemplo, a la ida Pinazo envió un chasque a uno de los caciques para solicitarle que acercara a los cautivos que tuviese en sus tolderías a la expedición y pedirle que informara a otros que hicieran lo mismo. Destacamos la comunicación que Pinazo mantenía con algunos de ellos, como por ejemplo Catuén y Toro, ya que ambos le enviaron chasques para saber "cómo se habían portado los indios de adentro". ${ }^{18}$

En esta oportunidad, Pinazo también envió una extensa carta a las autoridades de Buenos Aires desde la laguna Cabeza del Buey y dejó consignado en el diario que "el día 16 se hizo alto todo el día en este paraje, y se despachó chasque al Excelentísimo Señor Virrey, dando parte a su Excelencia del regreso de la expedición" ${ }^{19}$ La carta fechada ese mismo día y desde ese mismo lugar da cuenta de los principales conflictos a los que se habían enfrentado a lo largo de la expedición, por lo que su contenido se asemeja a la del año anterior enviada desde un paraje cercano a Cabeza del Buey. ${ }^{20}$ Detalla algunas cuestiones relativas a la composición y estado de la comitiva y se aplica principalmente a las relaciones con los grupos indígenas entre las que destaca que "aunque en otras expediciones han concurrido muchos indios de las tres naciones que ocupan estos campos, en esta han sido con exceso". ${ }^{21}$ Además de las transcripciones de los diarios, presentamos un documento elaborado por Pinazo (Transcripción $\mathrm{N}^{\circ} 4$ ) luego de las tres expediciones consecutivas a su mando en el que detallan los cautivos rescatados en cada viaje. ${ }^{22}$ Esta pieza documental complementa la información contenida en los diarios relativa a la procedencia y la filiación de los cautivos rescatados.

En síntesis, hasta aquí detallamos algunas cuestiones sobre las tres expediciones con el objetivo de comprender sus particularidades en el marco general de la recolección de la sal en la década de 1780 en la frontera sur de Buenos Aires. Observamos cómo las cartas enviadas -al regresar la expedición- desde Cabeza del Buey unos días antes del arribo a Buenos Aires o Luján, así como los diarios con la información de lo sucedido día por día en el transcurso de la misma, son documentos que se complementan y nos permiten conocer con detalle los tipos de interacciones que se establecían entre los expedicionarios y funcionarios coloniales, por un lado, y los caciques y grupos indígenas por el otro. Entonces, entre los múltiples aspectos a considerar para el análisis de la documentación presentada podríamos mencionar la preparación de las expediciones, los parajes recorridos para llegar a las Salinas y los sujetos que se encontraban, como el comandante, los particulares, los caciques, los grupos indígenas, los cautivos, los baqueanos y los lenguaraces. Los aspectos económicos y relativos a la composición de las expediciones a Salinas han sido estudiadas por Taruselli (2005-2006) mientras que Nacuzzi (2013) se ha centrado en el análisis de las relaciones interétnicas. En este trabajo será central el estudio de la dimensión territorial en estas incursiones, es decir, de las interacciones sociales - de los sujetos que concurrían desde la parte colonial y los grupos indígenas que se acercaban a ellos- desplegadas en los distintos parajes de la tierra adentro por los que transitaba la expedición. Así, atenderemos tanto a los espacios geográficos como a las relaciones sociales establecidas en ellos, como señalaremos en el siguiente apartado. 


\section{Antecedentes}

14 La colonia española se encargó de diversas maneras de proteger a los habitantes de la ciudad de Buenos Aires de los grupos indígenas que vivían en los territorios aledaños. Desde el momento del establecimiento de las guardias, fuertes y fortines de la frontera sur, las relaciones con los grupos indígenas y sus caciques se centraron principalmente en esos puestos fronterizos. Según Alemano (2015), a comienzos de la década de 1780 la política Vértiz implementó algunas estrategias para contrarrestar los efectos de decisiones anteriores que resultaron insatisfactorias entre las que destaca un plan de adelantamiento de los fuertes que resultó inadecuado, a lo cual se sumó el rechazo de la solicitud de paz por parte de algunos caciques aucas. En este mismo sentido, Pérez Zavala y Tamagnini (2012) sostienen que el plan de defensa y población de la frontera sur de Córdoba, sumado al fortalecimiento de las relaciones diplomáticas con los indígenas, inauguró un período de paz que prevaleció hasta 1815. Además, los funcionarios coloniales desarrollaron diversos mecanismos para proveer a la población de la ciudad de los recursos necesarios para vivir, como la sal. Es posible considerar a las expediciones de abastecimiento hacia las Salinas Grandes, que estaban en la tierra adentro, como parte del espacio de la frontera conocido por la agencia colonial y sus funcionarios, aunque los parajes localizados entre las guardias y la laguna de la Sal estaban controlados por los grupos indígenas de la región pampeana.

De este modo, el análisis de las expediciones hacia Salinas se enmarca en los enfoques teóricos y conceptuales acerca del estudio de las relaciones interétnicas en la frontera sur de Buenos Aires. Entre ellos, destacamos el concepto de "zonas de contacto" propuesto por Mary Louis Pratt (2011 [1992]) al referirse a los espacios donde se encontraron sujetos que hasta entonces se habían mantenido separados (histórica y geográficamente). La autora destaca las relaciones considerablemente estables que se establecieron entre ellos sin olvidar las condiciones de coerción, inequidad y conflicto producidas dentro de un sistema de dominación colonial. En este mismo sentido, la categoría de "complejo fronterizo" acuñada por Boccara (2005, p. 47) alude a las relaciones entabladas por diversos grupos en el contexto colonial en el marco de "un espacio de soberanías imbricadas formado por varias fronteras". El autor considera la complejidad y variabilidad de los grupos que circulaban en la frontera sur de Buenos Aires, los cuales atravesaron procesos de etnificación, normalización, territorialización, etnogénesis y mestizajes. Por su parte, Nacuzzi (2014a, p. 104) ha denominado "espacios de frontera" a aquellos extensos territorios habitados tanto por grupos indígenas como por la sociedad colonial caracterizados por su permeabilidad y porosidad, donde las personas interactúan en el marco del "constante reacomodamiento territorial y poblacional, en donde eran habituales la comunicación y el intercambio pacífico o conflictivo" y el establecimiento de relaciones esporádicas o permanentes.

En este sentido, los conceptos como "zona de contacto" (Pratt 2011 [1992]), "complejo fronterizo" (Boccara 2005) y "espacio de frontera" (Nacuzzi 2014a) nos permiten comprender las dinámicas de las expediciones hacia las Salinas en articulación con los enclaves fronterizos ya que destacan las relaciones entabladas por los distintos grupos a través del tiempo en los puestos de la frontera sur y en los territorios aledaños, ámbitos dinámicos y permeables con la presencia de individuos que circulaban en distintas direcciones. En relación a quienes circulaban por esos parajes, Roulet (2006) ha analizado 
la frontera -atendiendo al aspecto militar, político y demográfico- y la ha denominado como un "tercer término" en tanto era un espacio poroso, por fuera del control efectivo tanto de los hispanocriollos como de los grupos indígenas. En este trabajo tendremos en cuenta estas perspectivas para el análisis de la circulación y control del territorio por parte de los distintos grupos que circulaban por ellos durante la ejecución de las expediciones hacia las Salinas.

dio de la dimensión territorial de parajes por los que circulaban los expedicionarios al dirigirse hacia las Salinas se desprende de los documentos elaborados por el comandante de las incursiones. Es decir, nuestro análisis se basa en las apreciaciones de Manuel Pinazo sobre los parajes por los que circulaba, por lo que debemos atender a los autores que han señalado que "producir una representación del espacio es ya una apropiación, un dominio, un control" (Raffestin 2011 [1980], p. 102). Los conceptos de "espacio" y "territorio" no serían equivalentes ya que, siguiendo a ese autor, el espacio es previo al territorio, es lo "dado", aquello que se encuentra en el mismo nivel que la materia prima, por lo que es anterior a las acciones de los individuos. Esta perspectiva nos interesa porque sostiene que el territorio se genera a partir de un espacio en donde se despliegan relaciones sociales entre diversos sujetos. Desde el punto de vista de Benedetti (2014), el territorio como categoría heurística se diferencia de otras categorías geográficas ya que está asociada con el poder y con el sujeto social que lo define. Según el autor, cada territorio se define a partir de prácticas simbólicas y materiales por lo que constituyen "entidades geohistóricas, procesos abiertos y contingentes" (Benedetti 2014, p. 15). Por su parte, Enrique (2015) sostiene que el territorio es el espacio geográfico en articulación con las relaciones sociales que han sido construidas en él; según la autora, los grupos sociales realizan interpretaciones y usos de los territorios que generan una infinidad de "paisajes". En cuanto a los caminos, Curtoni (2007, p. 72) los concibe en relación con la decisión de conectar determinados lugares excluyendo otros, es decir, "como el producto de una intención social". Consideramos que las fuentes documentales que narran los sucesos ocurridos en las expediciones nos permiten indagar en las relaciones sociales entabladas entre las personas que concurrían a esos viajes y aquellas otras que vivían en los lugares por los que se desplazaban los expedicionarios.

Además, Enrique (2015, p. 144) ha definido las Salinas Grandes como un "nodo territorial", un área "de importancia estratégica donde confluían personas, recursos, intereses y significados". Según la autora, los nodos territoriales poseían límites variables ya que eran creados de modo dinámico por los actores sociales que los frecuentaban. Algunos nodos - como el fuerte del Carmen en el río Negro y los fortines próximos al río Salado de la actual provincia de Buenos Aires- eran controlados por los hispanocriollos mientras que otros - como las Salinas Grandes y la Sierra de la Ventana- se encontraban bajo el dominio de los grupos indígenas. Desde esta perspectiva, los relatos aquí publicados presentan una descripción acerca de los contactos en los parajes que se encuentran entre dos nodos territoriales controlados por distintos grupos: comenzaban y finalizaban en la guardia y frontera de Luján -a cargo de las autoridades coloniales- y tenían como punto máximo de avance las Salinas Grandes -bajo control indígena-. Creemos que los parajes intermedios entre la guardia de Luján y las Salinas Grandes también pueden entenderse como nodos territoriales en el sentido de Enrique (2015), ya que en ellos también circulaban personas de diversos grupos sociales, uno de los cuales controlaba el territorio. Si bien podemos reconocer distintos usos e interpretaciones de estos lugares por parte de los grupos indígenas y de los expedicionarios de la colonia a 
partir de los relatos, notamos que eran los primeros quienes poseían mayor dominio de las situaciones sucedidas en esos escenarios.

\section{El control del territorio}

19 Las relaciones entre los grupos indígenas y los funcionarios coloniales en los parajes de la tierra adentro adoptaron características variadas en función de los motivos que llevaban a los hispanocriollos a esos territorios. Las incursiones fueron organizadas a partir de diversos objetivos, como por ejemplo el reconocimiento del terreno, la recolección de recursos económicos, las expediciones para acordar las paces y aquellas otras con fines punitivos (Nacuzzi y Vollweiler 2017). Si bien en todas se entablaron relaciones interétnicas, las características de los encuentros estuvieron signados por los objetivos más específicos de cada expedición. En este trabajo nos centramos en las expediciones de aprovisionamiento de recursos económicos en las cuales la preocupación principal de los funcionarios, en cada viaje, era regresar a la frontera sur con las carretas cargadas de sal.

20 En este contexto, los funcionarios coloniales se desplazaban por el territorio que separaba la guardia de Luján de la laguna de la Sal abastecidos de los efectos necesarios para alimentarse durante el viaje, para cargar sal en la laguna y para protegerse de los encuentros con los grupos indígenas. En los tres diarios analizados se especificaba la cantidad de carretas, carretillas y carretones -de propiedad de los particulares que integraban la expedición - con las que emprendían la marcha y, en algunos casos, se informaba cuando se sumaban otras más unos días después del inicio del recorrido, en algún paraje cercano a la guardia de Luján de camino hacia las Salinas Grandes. Además, se dirigían hacia la tierra adentro con cuerpos de blandengues, de milicias y de pardos y con elementos de artillería entre los que destacamos los cañones, los carros, las municiones de guerra y los cohetes para proteger a los expedicionarios. ${ }^{23}$ Asimismo, en los diarios se especificaban los alimentos para la tropa y los particulares -las cantidades de cabezas de ganado, tabaco, yerba, arroz, azúcar, aguardiente y vino- así como los efectos necesarios para "decir misa" y para curar a los heridos en caso de que los hubiese.

La marcha se emprendía con una disposición militar que era minuciosamente detallada por Pinazo en sus diarios; la comitiva estaba conformada por una "vanguardia", un "centro" y una "retaguardia" con sutiles diferencias año tras año. En 1786, 1787 y 1788 la vanguardia estuvo "mandada alternativamente por los oficiales de mayor graduación" con cuarenta hombres los primeros dos años; en el centro se dispuso la artillería al frente seguida por las carretas, con una columna a su derecha de entre 250 y 300 hombres rodeada a los costados por las boyadas y caballadas con cincuenta hombres destinados a su arreo y cuidado. Por último, la retaguardia estaba "mandada alternativamente por los respectivos oficiales con 30 hombres". ${ }^{24}$ Observamos entonces que las modalidades seleccionadas para el desplazamiento de las tropas y el tránsito por el territorio estaban previstas y que, pese a algunas sutiles diferencias, se repetían todos los años.

$22 \mathrm{Al}$ aproximarse a las Salinas Grandes, la escolta se encargaba primero de reconocer los alrededores de la laguna para luego asegurarse de que los miembros de las comitivas no correrían peligro. Pinazo escribió en cada uno de sus diarios cómo se habían repartido en ese paraje con sus armas, con el objetivo de resguardarse de los grupos indígenas que hubieran querido atacarlos. ${ }^{25}$ Sostuvo que dispusieron de tres partidas en las cuatro direcciones de los puntos cardinales con "las señas de un cohete, del que debían usar en caso de distinguir gentes, humos o fuegos" ${ }^{26}$ y especificó cómo debían accionar si 
divisaban grupos indígenas. Además de preocuparse por los alrededores, también colocó artillería en el campamento -un cañón al este, otro al oeste y dos a la retaguardia, sumado a "los cinco esmeriles al cuidado todos de los artilleros sostenidos de 25 hombres" ${ }^{27}$ - Estas disposiciones implicaban que durante los días de permanencia en las Salinas Grandes para la recolección de la sal, el comandante, la tropa y los particulares ocupaban la laguna y sus alrededores por lo que le imprimían al territorio características diferentes de las que poseía la mayor parte del año bajo el control de los grupos indígenas.

Así, en estas expediciones de aprovisionamiento de sal, los funcionarios se dirigían hacia la tierra adentro con los enseres que necesitaban y en el orden que creían conveniente para transitar por el territorio ya que la experiencia de incursiones anteriores les había permitido aumentar el conocimiento del terreno y mejorar las condiciones de las subsiguientes. Una de las formas de observar este aspecto es atendiendo a las similitudes y diferencias de los itinerarios recorridos a partir de los nombres de los parajes mencionados en los diarios. Pinazo registró los lugares por los que habían transitado en cada viaje en que comenzaba en la guardia de Luján, recorría parajes habitados y frecuentados por grupos indígenas y finalizaba en la laguna de la Sal. Además, al comparar el itinerario en los tres diarios notamos que en 1786, 1787 y 1788, al menos a la ida o al regreso caminaron por las lagunas las Saladas, la laguna de Chivilcoy, el río Salado, la laguna Palantelén, lagunas Las Hermanas, Cruz de Guerra, los Monigotes y Cabeza del Buey, cañada Larga, laguna del Monte, de los Paraguayes y de los Patos. La repetición de estos parajes en las expediciones hacia las Salinas nos indica que el trayecto seguido para arribar y regresar a la laguna de la Sal era similar en cada oportunidad. Incluso, algunos de los parajes nombrados coinciden con pueblos actuales, por lo que entendemos, siguiendo a Martínez Sierra (1975), que muchos pueblos se establecieron en lugares que conformaban rutas de circulación muy antiguas, probablemente indígenas. Entonces, el camino seguido para arribar a la laguna de la Sal estaba establecido, si bien podía sufrir modificaciones (Enrique y Vollweiler 2016). En este sentido, la comparación de los recorridos de los viajes en 1786, 1787 y 1788 permite ejemplificar las formas en que se incorporaban $-\mathrm{y}$ bautizaban - nuevos parajes. ${ }^{28}$

En el diario de 1787, Pinazo narró cómo, al llegar a una laguna por ellos desconocida, decidió bautizarla con "el nombre del Socorro de San Nicolás de Bari, por haber llegado a ella en este día" y, para reconocerla en futuras expediciones, describió su localización -“dista del camino una legua corta a la derecha de él"-, su extensión -“tendrá de largo como dos cuadras, y las mismas de ancho"-, la composición del suelo - "tosca"-, su forma -"le sale un ramblón a modo de arroyo al norte [...] y otro al sur con las mismas circunstancias"- y las características del agua que poseía - "muy buena" y "algo salobre".$-{ }^{29}$ En el viaje realizado al año siguiente, registró la misma laguna en su diario una vez pasadas "las Hermanas hicimos alto frente de la laguna del Socorro San Nicolás de Bari" 30 - y también de regreso - arribaron a la laguna de "las dos Hermanas, (habiendo pasado la laguna del Socorro de San Nicolás de Bari)" ${ }^{31}$. Este caso representó una modificación en el territorio, ya que en el diario de 1786 no se registraron indicios de esta laguna (porque no la habían recorrido o porque no la habían bautizado) mientras que en el de 1788 este paraje de la tierra adentro formó parte del itinerario y ya poseía un topónimo otorgado por los funcionarios coloniales.

Si bien una de las formas de conocer y controlar el territorio era a partir de la atribución de nuevos topónimos a los hitos geográficos por los que transitaban, también era habitual la identificación de los parajes a partir de otros criterios, como por ejemplo los lugares 
habitados y frecuentados por algunos caciques. En este sentido, en los tres viajes analizados se observan relaciones entre los funcionarios coloniales y los integrantes de las tropas con el cacique Catuen, sus familiares y los grupos indígenas que estaban con ellos. Las mismas incluyeron la remisión de mensajes para negociar los encuentros, las visitas del cacique al comandante o el envío de familiares en su lugar, el intercambio de bienes, entre otros. No nos sorprende entonces cuando en 1788, al arribar al lugar en el que se habían encontrado con el cacique los años precedentes, Pinazo identificó un paraje como "el médano del cacique Catuen". ${ }^{32}$ Este tipo de referencias son un indicio, por un lado, de que los grupos indígenas controlaban esos parajes y, por el otro, del reconocimiento de esta situación por parte de los funcionarios coloniales: circulaban por parajes que si bien conocían - debido al carácter periódico de las expediciones- no controlaban.

\section{Las relaciones interétnicas en el camino hacia las Salinas Grandes}

Los enseres y bienes que se llevaban a la tierra adentro así como el orden en el que caminaban estaban relacionados con la previsibilidad que necesitaban para desplazarse por el territorio habitado por los grupos indígenas y desconocido para ellos. Esto explica también la repetición de los itinerarios año tras año, ya que volvían a transitar por los parajes en los cuales habían establecido relaciones pacíficas y ventajosas con los grupos indígenas como el intercambio de bienes, mensajes y cautivos. ${ }^{33}$ Debido a que el objetivo de este tipo de incursiones de recolección de recursos dependía de las buenas relaciones con los grupos indígenas, entre las medidas de seguridad que tomaban primaban actitudes defensivas más que ofensivas (a diferencia de otras expediciones como las punitivas) ${ }^{34}$.

Con el objetivo de indagar en las interacciones entre los grupos indígenas y los miembros de las comitivas coloniales en la tierra adentro, registramos los lugares en los cuales se intercambiaron mensajes, bienes y cautivos en 1786, 1787 y 1788 . Entre ellos, notamos que en la cañada Larga y sus alrededores -aproximadamente a mitad del camino, a menor distancia de las Salinas que de la guardia de Luján - se entablaron variadas negociaciones con caciques en los tres años de marcha. Es notorio que los caciques conocían las locaciones de las comitivas ya que en reiteradas ocasiones enviaron mensajes, mediante chasques, desde sus tolderías al comandante para acordar un inminente encuentro. En 1786 Catuen envió un mensaje a Pinazo con algunos de sus hombres que se acercaron a la expedición y al día siguiente llegaron "los Lincones, Catuenes, y Cancupis" 35 junto "con 150 indios, en diversas tropillas significando querían la paz" quienes luego de intercambiar presentes dieron lugar a "sus tratos", los cuales incluían "pieles, plumeros, ponchos, mantas, y riendas". ${ }^{36}$

En 1787 se acercaron primero "los caciques Antonio y Guenquene acompañados de muchos indios e indias" y luego "los caciques Cantupi y Currutipay" con un grupo de su gente, todos para negociar con sus productos. ${ }^{37}$ En 1788 estas situaciones de aproximación de los caciques con más integrantes de sus parcialidades también se mantuvieron ya que se acercó una de las mujeres de Catuen con "considerable porción de indios e indias, trayendo muchos caballos, plumeros, cueros de venado, y otras pieles, riendas, y lazos 
para vender" así como "el cacique Güanquenecul" con un grupo para vender diversos productos. ${ }^{38}$

Si bien la cañada Larga fue el paraje más significativo en relación a estos encuentros, en otros lugares como la laguna Cabeza del Buey, la laguna del Monte, la laguna del Juncal y los manantiales del Petiso también se entablaron relaciones pacíficas con los grupos indígenas que nos permiten entender uno de los motivos que llevaba a los funcionarios a repetir el paso por determinados parajes en sus recorridos. Dadas las relaciones establecidas con los grupos indígenas en 1786 durante la expedición -seguramente basadas en las interacciones ocurridas en incursiones anteriores-, no nos sorprendemos que la cañada Larga formara parte del itinerario en las tres expediciones aquí analizadas. Desde ese paraje se podía negociar con algunas parcialidades luego de ciertas formalidades - como el envío de mensajes con los caciques y de la ratificación de las paces -. Así, esta cañada se conformó como un paraje intermedio entre la guardia de Luján y las Salinas, un paraje de relevancia para los expedicionarios y los caciques, que se mantuvo en las tres expediciones. Creemos que, dado que este tipo de interacciones era muy común, en otras expediciones - antes y después de estos años- otros parajes localizados en los itinerarios seguidos pueden haber funcionado como nodos intermedios entre distintos puntos de partida y de llegada.

Los intercambios de mensajes, obsequios, bienes y personas también sucedían en la misma laguna de la Sal, donde se observan este tipo de relaciones entre los funcionarios y los grupos indígenas. En 1786 se acercaron a las Salinas a intercambiar bienes las parcialidades de Catuén, Caneupy y Lincon y los caciques Canoy Paiguén, y Querel Tipay; en 1787 fue el cacique Currutipay con un grupo de su gente a vender, también se acercaron dos hijos de los caciques Anteguan y Cariguan con varios otros a quienes les solicitó Pinazo que acercaran a los cautivos -aunque luego esto no se concretó- y el cacique Guenquene le envió un mensaje a través de dos hombres de su parcialidad. Al año siguiente, los caciques Paynetu, Toro, Painegüen, Curral y Santiago fueron cada uno con sus parcialidades a vender sus productos a la laguna de la Sal mientras la comitiva a cargo de Pinazo se encontraba allí. Ese mismo año también se acercó el "cacique Catumida con varios indios, y otros de la parcialidad del cacique Antuan, de los cuales conoció Don Blas Pedrosa dos que tenían dos cautivas" y, luego de negociar, rescataron a las cautivas, tal como sucedió con otra mujer que "conoció el citado Pedrosa" 39 entre el grupo que llegó con el cacique Paneigüen..$^{40} \mathrm{El}$ rescate de individuos en las expediciones a las Salinas también era relevante para la colonia, como lo demuestran las órdenes que recibió Pinazo en las que se le encomendaba esta tarea así como el documento por él elaborado en 1788 con información de todos los cautivos rescatados en las tres expediciones consecutivas por él comandadas (ver Transcripción № 4).

31 En estas incursiones, los expedicionarios se dirigían desde la guardia de Luján hacia la laguna de la Sal mientras que los grupos indígenas se desplazaban desde sus tolderías en la tierra adentro hacia los distintos lugares en los que se encontraban con los expedicionarios. Los miembros de las comitivas caminaban durante días para arribar a la laguna de la Sal mientras que los grupos indígenas podían acercarse a la expedición y retirarse de la misma velozmente ya que conocían con mayor detalle los territorios por los que circulaban los viajeros y tenían sus tolderías más próximas. A modo de ejemplo, en 1786 cuando la comitiva se encontraba en la laguna de la Sal, se acercaron a ellos tres indígenas: "uno de los toldos del cacique QurrellTipay" y dos que ya se habían cruzado con ella en el trayecto entre la cañada Larga y la laguna de los Patos. ${ }^{41}$ Es decir, los grupos 
indígenas tenían la posibilidad de evitar a los miembros de las expediciones o de acercarse a ellos -en la laguna de la Sal o en el camino hacia ella-, posibilidad garantizada por el conocimiento del territorio en el que se encontraban y, además, por la cercanía de sus toldos y la presencia de otros individuos de sus parcialidades en esos territorios. La comitiva colonial, en cambio, debía mantenerse unida ya que la mayoría de sus integrantes, a excepción de los baqueanos, desconocía en detalle los parajes y caminos por los que transitaban.

Entonces, los grupos indígenas y sus caciques circulaban por esos parajes de forma cotidiana ya que sus tolderías se encontraban allí y este conocimiento diferencial del territorio les otorgaba ciertas ventajas en las negociaciones con los funcionarios coloniales. En 1788, cuando la expedición se encontraba en la laguna de la Sal se acercó el cacique Canevayon con integrantes de su parcialidad entre los que se encontraba Tripán, quien estaba "casado con una cautiva llamada Francisca Bengolea". ${ }^{42}$ En esta ocasión "un hermano de ella (que iba en la expedición)" fue acompañado por tres indios hasta los toldos "y el día siguiente la trajeron". ${ }^{43}$ En este caso, los toldos en donde tenían a la cautiva se encontraban a tan solo un día de marcha de ida y regreso desde las Salinas mientras que la guardia de Luján desde donde había partido la expedición estaba a quince o veinte días de camino. Observamos que, en el trayecto entre la guardia de Luján y las Salinas Grandes, eran los grupos indígenas los que poseían un mayor dominio de los eventos. Por eso, por ejemplo, las mujeres de los caciques Catuen y Lorenzo podían responderle a Pinazo -ante su pedido de que le acercaran a las cautivas en su poder-que fueran a rescatarlas "a los toldos". Para el comandante no era una tarea sencilla ya que, además de la escasez del agua, debía encargarse de otros asuntos (en esa ocasión, de un conflicto entre dos indígenas y dos soldados)..$^{44}$ Estas posibilidades diferenciales de transitar por el territorio se evidenciaban en otros aspectos además de los rescates de cautivos, como por ejemplo en la información que poseían los grupos indígenas en relación con aquella en poder de los hispanocriollos. En la expedición de 1787, por ejemplo, cuando se encontraban en la laguna del Juncal, Catuen le recomendó a Pinazo mantenerse alerta ya "que al otro lado de la sierra Grande se hallaban muchos indios Teguelchues" 45 que podían atacarlos.

33 En este contexto, entendemos las interacciones entre los sujetos en el marco de lo que hemos denominado como "frontera móvil" (Nacuzzi y Vollweiler 2017) al referirnos a las situaciones que se generaban al dirigirse los funcionarios coloniales hacia territorios que, si bien excedían el espacio conocido como la frontera sur, permitían la creación de escenarios en los cuales también se reunían representantes de distintas sociedades. Los encuentros se producían generalmente cuando alguna parcialidad se acercaba a la expedición, como en 1786 cuando se encontraban en la laguna del Monte y los "alcanzaron dos tropillas de indios, e indias, que unos y otras componían 65, que venían a tratar" ${ }^{46}$ En otras ocasiones los contactos se negociaban previamente como en 1787, en las inmediaciones de Cabeza del Buey, cuando la partida reconocedora se encontró con el "cacique Catuen con sus indios" quienes estaban esperando a la comitiva. Más tarde ese mismo día, Catuen le envió un mensaje a Pinazo para que se dirigieran hacia allí y, unos pocos días más adelante, fue el cacique con integrantes de su parcialidad hacia la expedición. Según Pinazo, se mostraron "todos tan sin cuidado, que manifestaban la mucha confianza, que tenían de nuestra buena fe". ${ }^{47}$ las expediciones influían en los puestos fronterizos. A fines de 1788, por ejemplo, en la 
frontera de Luján se presentó el cacique Lancan "con diez indios y ocho chinas [...] con los efectos que acostumbran" $48 \mathrm{y}$, debido a que este mismo cacique se había acercado a la expedición de "Salinas el año próximo anterior" en la que había dado "pruebas de amistad" ${ }^{49}$ regresó de la frontera de Luján con un presente unos días más tarde. Es decir, los encuentros interétnicos que se generaban en las expediciones hacia las Salinas tenían relación con los contactos de los puestos de la frontera sur en donde los funcionarios poseían mayor control de las situaciones. Sin embargo, como hemos observado, en las incursiones hacia la tierra adentro las relaciones sociales que se producían en la laguna de la Sal y en los parajes intermedios entre la guardia de Luján y las Salinas estaban enmarcadas en el control que ejercían las parcialidades indígenas sobre esos territorios.

\section{Consideraciones finales}

Nos hemos referido a las Salinas Grandes en las expediciones que la agencia colonial realizó durante tres años consecutivos de la década de 1780 en el marco de un período más amplio de incursiones que comenzaron en el siglo XVIII, continuaron durante la Colonia y en el período independiente. Partimos del análisis de la dimensión espacial y territorial de aquellos parajes por los que marchaba la comitiva colonial cada vez que se dirigía desde la guardia de Luján a las Salinas e hicimos énfasis en las relaciones entre los grupos indígenas que habitaban esos territorios y los expedicionarios que por ellos transitaban. Observamos que eran los caciques y sus parcialidades los que tenían mayor control en las negociaciones ya que poseían un conocimiento diferencial del territorio que los posicionaba en una situación ventajosa.

Asimismo, expusimos las distintas estrategias implementadas por el comandante, la tropa y los demás integrantes de la expedición para transitar por lugares lejanos de los puestos fronterizos y cercanos a las tolderías indígenas. Sostuvimos que las acciones por ellos desarrolladas tomaron características defensivas más que ofensivas, acordes con el objetivo de extraer sal y negociar con los grupos indígenas. Aunque los expedicionarios temían perder el control de la situación, los encuentros pacíficos con los grupos indígenas y sus caciques nos muestran que esas interacciones también eran aprovechadas para comerciar y para rescatar cautivos, entre otros aspectos, en parajes intermedios como la cañada Larga y en la laguna de la Sal. Observamos que las relaciones interétnicas que se daban en el territorio adquirían distintos matices durante estas expediciones ya que las mismas eran contextuales, variaban en cada momento y lugar en función de los intereses de los sujetos involucrados y de su conocimiento del territorio.

Asimismo, relevamos algunas acciones desplegadas por parte de los distintos grupos en los parajes de la tierra adentro -como el intercambio de productos y el rescate de cautivos - que los llevaban a implementar estrategias para conocer y controlar los lugares por los que circulaban. A partir de un planteo previo (Nacuzzi y Vollweiler, 2017), caracterizamos las interacciones entabladas durante las expediciones a las Salinas como parte de una frontera móvil que, a diferencia de las negociaciones establecidas en los puestos fronterizos que se encontraban en lugares delimitados del espacio, se configuraba durante los viajes que comenzaban en la guardia de Luján, llegaban a la laguna de la Sal como el punto más lejano y regresaban al mismo lugar del que habían partido. Este movimiento acercaba a los funcionarios a las tolderías, por lo que las relaciones establecidas con los grupos indígenas, si bien trataban los mismos asuntos, no eran idénticas. En este sentido, y siguiendo el planteo de Enrique (2015), postulamos que los 
parajes intermedios entre la guardia de Luján y las Salinas Grandes pueden considerarse como nodos territoriales controlados en este caso por grupos indígenas.

\section{Fuentes}

Archivo General de la Nación (AGN), sala IX, legajos 1-5-3, 1-6-3, 13-8-17 y 19-3-5.

\section{Transcripciones}

En las transcripciones aquí presentadas se modernizó la ortografía, se desplegaron las abreviaturas y se indicaron los cambios de folio. La numeración de los folios está expresada en los casos en los que los documentos lo indican. Los corchetes indican agregados personales.

\section{Transcripción № 1}

Archivo General de la Nación (AGN), Sala IX (colonial), legajo 19-3-5, ff 560 a 567v.

Diario de Manuel Pinazo sobre la expedición a Salinas de 1786

/f. 560/ Don Manuel de Pinazo maestre de campo general reformado, [de la] jurisdicción de Buenos Aires.

Habiendo sido nombrado, comandante de la presente expedición, a Salinas, por el Excelentísimo Señor Marqués de Loreto, Virrey Gobernador y Capitán General de estas provincias, por su despacho de 19 de julio, del presente año.

Me presenté, en la frontera de Luján, en $1^{\circ}$ de octubre, del mismo año, día señalado por bando publicado; en Buenos Aires, para que concurriesen allí todas las carretas, cuyos dueños voluntariamente destinasen, a esta expedición; igualmente que la tropa, que de orden del propio Excelentísimo Señor Virrey; debiere escoltarla, y en su virtud se me presentaron, hasta el día 6.

\begin{tabular}{|l|l|l|l|l|}
\hline Cuerpos & Capitanes & Tenientes & Subtenientes & Tropa inclusos sargentos, cabos y tambor \\
\hline De blandengues & 2 & 1 & 1 & 200 \\
\hline De milicias & 2 & 2 & 2 & 150 \\
\hline De pardos & 1 & 1 & 1 & 50 \\
\hline Total & 5 & 4 & 4 & 400 \\
\hline
\end{tabular}

\begin{tabular}{|l|l|l|l|}
\hline & carretas & Carretillas & carretones \\
\hline 253 & 12 & 5 \\
\hline
\end{tabular}

Y habiendo pasado revista a la tropa, y después reconocido las carretas, por su hubiere algunas, que por falta de aperos, boyada, o peones pudieran embarazar las marchas, dispuse la de la expedición, en estos términos.

Vanguardia

Mandada alternativamente, por los oficiales de mayor gra /f. 560v/ duación con 40 hombres.

$\underline{\text { Centro }}$ 
Al frente la artillería, y después las carretas, y en columna a su derecha 280 hombres, y a uno y otro costado las caballadas y boyadas con 50 hombres para el arreo, y cuidado de los caballos.

$\underline{\text { Retaguardia }}$

Mandada alternativamente por los respectivos oficiales con 30 hombres.

Con este orden emprendimos la marcha el citado día a las 8 de la mañana, y a las 11 1/2 paramos, habiendo caminado 5 leguas; habiendo dispuesto los resguardos correspondientes, siendo prevención que así este paraje como los demás, donde se acampó en todo el viaje, fueron siempre escogidos por de mejores aguadas.

Día 7. Marchamos a las $10 \frac{1}{2}$ de la mañana, y pasamos las Saladas, avanzándonos como 3 leguas más adelante. De aquí se retiró el teniente Don Antonio Martinez, por enfermo, y se desertaron dos milicianos y cuatro pardos de cuyo hecho dio aviso al Comandante de Frontera, para su inteligencia: anduvimos este día 6 leguas.

Día 8. Oímos misa, y marchamos a las 8 de la mañana y pasamos la cañada de Chivilcoy, que la hallamos inundada de agua, avanzando 3 leguas más. Y anduvimos como 8 leguas poco más, o menos.

Día 9. Salimos del lugar dicho, y pasamos el salado, y llegamos a Palantelén, a las 11 1⁄2 del día, habiendo caminado 6 leguas /f. 561/ más, o menos. Aquí se paró el resto del día esperando a que llegase el baqueano Eusebio Caraballo con algún ganado.

Día 10. Marchamos a las 5 de la mañana, y llegamos a mediodía, a las Dos Hermanas, que distan de Palantelén de 5 a 6 leguas, en dicho Palantelén dejó el comandante una partida de 10 hombres, con un cabo, con orden de que si no llegaba el dicho Caraballo nos alcanzasen al otro día. A la tarde marchamos, y llegamos a una distancia de 3 leguas del médano Partido: se caminaron este día de 9 a 10 leguas.

Día 11. Salimos del lugar dicho a las 6 de la mañana, y paramos a las 11 del día como 2 leguas distantes de la Cruz de Guerra. Aquí tuvo el comandante noticia de los exploradores haber hallado algunos toros muertos por los indios: que habían sacado las pieles para coletos. A las 2 de la tarde marchamos, y a las $4 \frac{1}{2}$ llegamos a la Cruz de Guerra. Esta noche tuvimos una gran tormenta de viento; agua, y truenos, y llegó la partida dicha.

Día 12. Día de la virgen del Pilar, no pudo el capellán decir misa, por el tiempo, marchamos a las 8, y a medio día paramos en el médano llamado los Monigotes, que dista de la Cruz de Guerra, cinco leguas, hicimos medio día, y a las $2 \frac{1}{2}$ de la tarde, marchamos hasta las 6 , que mandó el comandante parar. Se andarían $3 \frac{1}{2}$ leguas.

Día 13. Caminamos a las 6 de la mañana, e inmediatamente vino una tormenta que por la lluvia nos obligó a parar a las $11 \frac{1}{2}$ después de haber andado como 5 leguas, dejando a nuestra retaguardia la laguna del Uncal, que se halló seca. Este mismo día, a cosa de las 10, alcanzó Eusebio Caraballo, al comandante, con cuatro más sin ganado alguno, con ánimo de acompañarlo en la expedición como lo ejecutó, paramos el resto del día, y esta noche tuvimos / f. 561v/ tuvimos [sic] una disparada de caballos de la caballada de los arroyos y Areco, de suerte que se perdieron más de 100.

Día 14. Marchamos a las 6 de la mañana, y a poco andar nos asaltó un viento que casi, nos sacaba de los caballos. Este día solo paramos a mudar bueyes, caminando, hasta las 5 de la tarde. $Y$ anduvimos como 9 leguas, y paramos como $2 \frac{1}{2}$ o 3 de la Cabeza del Buey.

Día 15. Oímos misa, caminamos a las 6 de la mañana. Y llegamos a la Cabeza del Buey a las $9 \frac{1}{2} 2$, en donde hicimos alto y a la $1 \frac{1}{2}$ de la tarde marchamos hasta las 5 y $1 / 2$ que paramos en una laguna sin nombre, antes de parar se avistó un humo que hicieron los indios al frente, no se pudo 
reconocer por estar muy retirado. Este día anduvimos 7 leguas, y sucedió que a un blandengue de la compañía del Salto, le dio una manotada un caballo en la cara, que le partió la mitad de ella, con gran parte de las narices, por el cirujano que llevamos anduvo tan eficaz, que pudo hacerle unir, aquella parte de la cara y narices.

Día 16. Marchamos hora y $1 / 2$ ante[s] de amanecer, y paramos, al medio de la cañada de los Zapatos. A la tarde marchamos a las 2, y a las cinco paramos en la laguna del Tigre habiendo caminado como 8 leguas. A las 7 de la noche llegó el piloto Don Pablo Zizur, escoltado de 20 blandengues, enviado por el señor virrey, para ciertos fines, con cortas de su excelencia señor gobernador, y del ilustre Cabildo, para el comandante.

Día 17. Se dio descanso todo el día en este mismo lugar y respondieron a otras cartas. Habiendo la partida de blandengues propuesto quería salir de noche por no encont /f. 562/ trarse con los indios, se ejecutó así.

Día 18. Marchamos a las 6 y $1 / 4$, y caminamos hasta las 11 1⁄2 que paramos en unos médanos habiendo pasado la cañada Larga, se hallaron a los costados varios médanos con agua, y hubo mucha caza de todas especies. A la tarde marchamos a las 2 y $1 / 2$ y paramos a la falda de una cañada que estaba a nuestra izquierda la que se halló, llena de agua, e inmediata a una laguna salada, que tiene más de 3/4 de legua de largo. Y anduvimos este día de 7, a 8 leguas.

Día 19. Marchamos a las 6 de la mañana, y a las 10 1/2 paramos en unos médanos todos con agua, hallamos la cañada (que en otras expediciones han dado mucho trabajo por la abundancia de agua) secas, no faltando a los costados agua para la tropa, y animales, anduvimos 4 leguas. A la tarde paramos para que se habilitasen las gentes de junco para los planes de las carretas. Esta tarde llegaron seis indios, con la noticia de que al otro día vendría más porción, entre la cual enviaba el cacique Catuén, mensaje al comandante.

Día 20. Marchamos a las 4 de la mañana, y caminamos hasta las $10 \frac{1}{2}$ anduvimos 6 leguas poco, más o menos, y antes de parar llegaron con 150 indios, en diversas tropillas significando querían la paz, y ratificando la que Su Excelencia les tenía dada, vinieron los Lincones, Catuenes, y Cancupis, haciéndole estos dos últimos una grande relación al comandante que explicada por el lenguaraz Francisco Almirón, se dirigía a ratificar la paz, y sacarle al comandante el regalo que en semejantes ocasiones suele hacérseles a estos caciques quienes también regalaron a dicho comandante dos ponchos. A la tarde marchamos como 2 leguas, por dar lugar a dichos indios /f. $562 \mathrm{v} /$ para sus tratos, que se compone de pieles, plumeros, ponchos, mantas, y riendas, y paramos entre unos médanos de agua que hay en una, y otra parte del camino. Este mismo día dejamos a nuestra derecha una gran cañada llena de agua que parece un río, pero es salada, los indios se embriagaron esa noche; pero no resultó novedad alguna.

Día 21. Estuvimos en este mismo lugar parados hasta mediodía, porque los indios suplicaron al comandante les diese más tiempo para concluir sus tratos. A la tarde marchamos, y paramos a vista de la laguna del Monte. Este tendrá muy cerca de un cuarto de legua de largo, anduvimos como 4 leguas, algunos de los indios se fueron esa tarde, y otros nos acompañaron algún trecho: esta misma noche dieron parte al comandante que un soldado de la compañía de la guardia de Rojas, se había huído; porque habiendo perdido un sable, y siendo reprendido por este hecho del capitán Don Fernando Navarro, no [a]pareció más: este tal es casado en los Arroyos: esta misma noche nos cayó un grande aguacero.

Día 22. No dijo misa el padre capellán por la lluvia que duró hasta las nueve del día, y así marchamos, pasamos el monte dicho, y paramos a las 12, costeando la laguna de dicho monte, a nuestra izquierda: a la tarde caminamos y paramos a las 6, en una cañada que a la derecha, tenía una laguna de mucha agua dulce, y mucho junco, aquí nos alcanzaron dos tropillas de indios, e indias, que unos y otras componían 65, que venían a tratar, anduvimos como 4 leguas, costeando 
la dicha laguna /f. 563/ del Monte, que alcanza hasta san Lucas, y dista de dicho monte más de 16 leguas.

Día 23. Caminamos a las $4 \frac{1}{2}$ de la mañana, y habiendo caminado como 3 leguas, mandó el comandante hacer alto, porque un peón de la tropa de Don Juan Diego Flores iba enfermo, y pidió confesión, luego marchamos, y a las 11 paramos en frente de una laguna que está a la izquierda del camino en una cañada; a la tarde marchamos hasta la laguna de los Paraguayés estas son 4 en una misma cañada inmediatas unas, de otras toda[s] dulce[s] dejando a nuestra izquierda entre la laguna del Monte, y los caminos, una laguna de buen tamaño dulce, siguiente [sic] siempre la del Monte, que remata en San Lucas.

Día 24. Marchamos a las 5 de la mañana lloviendo, y con un frío, muy grande, cerca de mediodía paró el agua, pasamos la laguna Larga, y otras distintas que dejamos, a un lado y otro del camino paramos a las 11 1/2, y luego llegaron 13 indios con 7 chinas indias, a tratar, y vender sus efectos, $\mathrm{y}$ nos acompañaron este día. A la tarde marchamos, y poco antes de las 6, divisaron los exploradores de la vanguardia, 5 indios, y dos indias, que venían de los toldos del cacique Canuy, Paiguen, e iban a los de Catuén quienes se recelaron de nosotros, y se huyeron dos; pero luego éstos se enteraron de nuestra buena fe, caminamos este día de 8 a 9 leguas.

Día 25. Marchamos a las 4 y 27 minutos, pasamos la cañada que está antes de llegar a la laguna de los Patos, y a las 7 y 1/2 pasamos dicha laguna, dejando 2 más a nuestra izquierda, a las 10 menos 8 minutos llegamos a la laguna de la Sal, dejando a nuestra /f. 563v/ izquierda 3 lagunas, bastante grandes. Se halló la laguna de la Sal dicha llena de agua, por cuyo motivo, no se pudo coger flor de dicha sal.

Día 26. Marcharon boyadas, y caballadas a los manantiales que dista de dicha laguna con $3 / 4$ de legua, y el comandante con el capitán Don Fernando Navarro, siguieron a dicho paraje con la escolta que se nombró para el resguardo de dichas boyadas y caballadas: de allí despachó el comandante 5 partidas de a tres hombres cada una, nombrando de cabo al que parecía de más juicio, la primera se despachó al sur, de dicha laguna[,] la segunda al este, que es la entrada que tiene dicha laguna por el bajo de la Barranca, la tercera al poniente, y las dos últimas al norte de dicha laguna dándoles a cada una, las señas de un cohete, del que debían usar en caso de distinguir gentes, humos o fuegos como asimismo en caso de divisar gentes en gran número, $\mathrm{e}$ inmediatos respecto a los muchos médanos que hay en este paraje, y que podía suceder que aunque quisiesen avisar si los enemigos venían a insultarnos llegaría el aviso junto con ellos que en semejante caso disparasen el cohete siguiendo al mismo tiempo a incorporarse con la escolta en dichos manantiales, mandando asimismo poner un centinela en el médano más elevado que hay en dichos manantiales, y por consiguiente otra inmediata al campamento, en un alto, para que esta divisase la seña de aquella, y aquella la de esta, después de haber dado estas disposiciones, se retiró dicho comandante, y capitán Don Fernando Navarro al campamento, en donde /f. 564/ colocó la artillería en la disposición siguiente. Un cañón a la parte del oeste sobre la barranca que da entrada al campamento. Otro al este de la misma barranca, y los otros dos a la retaguardia del campamento apuntando al norte, y formando línea con los cinco esmeriles al cuidado todos de los artilleros sostenidos de 25 hombres a más de continuadas rondas, por fuera de dicho campamento. Este mismo día llegaron tres indios a dicho campamento los dos que se huyeron el día 24, y uno de los toldos del cacique Qurrell Tipay, porque el día antes envió el comandante a un indio llamado Juancho, a decirle a este cacique que venía de buena fe, y surtió efecto el recado porque vinieron dichos tres indios: en este mismo día empezó el piloto a usar de su facultad, y la gente se ocupó en acopiar sal dentro de la misma laguna.

Día 27. Legaron diversos indios del cacique, Catuén, y Caneupy, a vender sus efectos: esta noche tuvimos una disparada de caballos, pero fue Dios servido que se atajasen con tiempo. 
Día 28. Concluyó su mensura el piloto, y halló que tiene la laguna de circunferencia cinco leguas, y dos tercios: en este mismo día, llegaron los caciques Canoy Paiguén, y Querel Tipay; con dos indios más, saliendo el comandante, con los capitanes Don Fernando Navarro, y Don Vicente Cortes, a recibirlos, los trajeron a la tienda de dicho comandante, se dieron las manos, se les dio de comer, y luego se fueron a donde estaban los demás indios de dicho Catuén, y nuestras gentes siguieron sacando sal.

Día 29. Pasaron los caciques dichos a despedirse del comandante y después de una larga arenga que le hicieron por medio del / f. 564v/ lenguaraz Francisco Almirón, y respondido por dicho comandante habiéndolos regalado se fueron muy gustosos habiendo tratando la paz, que se les concedió en nombre del excelentísimo señor virrey, a que propuso Canuy Paiguen, que en caso de que algunos de sus indios, viniesen [a] hacer daño unidos con los demás, siempre que fuesen cogidos los matasen porque él no podía remediarlo.

Día 30. No hubo novedad alguna más de haber venido algunos indios de los de Catuén, Lincon, y Canupy, [a] hacer trato, y estos se embriagaban, y el piloto seguía haciendo su reconocimiento.

Día 31. No hubo novedad alguna.

\section{Mes de Noviembre}

Día 1ํ. Salió el comandante, con los capitanes Don Fernando Navarro, Don Vicente Cortés, Don marcos Flores, y el piloto Don Pablo Zizur escoltados de 50 hombres al reconocimiento de una laguna, y monte que se halla a distancia de 3 leguas poco más o menos, y se divisa de un médano muy encumbrado de los muchos que hay en los manantiales: sucedió que antes de llegar a estos dieron parte al comandante que venía el cacique Qurrell Tipay, con otros indios y dos indas la una madre de dicho cacique, y recelándose este de llegar fue preciso hacer volver la escolta de suerte que no la viese dicho cacique, y llevarlo a él y sus indios al campamento, con cuyo motivo supo dicho comandante que este dicho cacique tenía una cautiva cristiana, trató de su rescate, y quedó en traerla, y después de haber vendido algunos ponchos, y mantas / f. 565/ que traían se fueron[.]

Día 2. Sigue el piloto su destino al reconocimiento de dicha laguna, y monte a cuyo efecto se le dio la escolta necesaria: este mismo día se nos desapareció una blandengue de la compañía de Rojas, sin poder saber su destino.

Día 3. Llegó la cautiva, con el cacique su amo, se juntó lo que pidió por su rescate, y se fue con Dios. Este día se nos vino un cautivo gallego llamado Blas Pedrosa, natural de La Coruña, que lo cautivaron en el saladillo yendo para Chile, en la tropa de carretas, en que iba un canónigo, y otros pasajeros, a quienes mataron. Este dio razón de hallarse los toldos de su amo Anteman a distancia de unas 16 leguas de la laguna de la Sal, y avisó de un insulto que habían cometido unos indios en la jurisdicción de Córdoba que distaba de la laguna como de 25, a 30 leguas. La noche de este día se vino una cautiva huida de los toldos del indio Quentou, inmediatos a los de Catuen que la cautivaron el año de 76 en la cañada de la Paja de esta jurisdicción, que teniendo noticia nos hallábamos en la laguna de la Sal, se huyó en un caballo, y caminó 4 días: esta dio noticia de otras cautivas que se hallan en poder de Catuén, y otros indios.

Día 4. Salimos de dicha laguna, para Buenos Aires, y llegamos a la laguna de los Patos, que dista de 2 leguas y $1 / 2$ a 3, en donde se hizo alto, y con motivo de ser el día de cumpleaños de nuestro Augusto Monarca, se hizo salva general de la artillería, como lo ha tenido de costumbre el comandante en todas sus expediciones.

Día 5. Después de oir misa marchamos a las 9, poco más / f. 565v/ o menos, y habiendo caminado como 2 leguas, paramos por haber habido varias quiebras de carretas. 
Día 6. Marchamos a las 5, y 5 minutos de la mañana y paramos a las 11, hasta el siguiente día por las quiebras de carretas[.]

Día 7. Marchamos a las $4 \frac{1}{2}$ de la mañana, y a las 10 y 3/4 paramos en frente de San Lucas, aquí se ocupó todo el resto del día, porque continuaron las quiebras; este mismo día, vinieron porción de indios, e indias al trato.

Día 8. Marchamos a las 3 y 1/2 de la mañana, y llegamos a la laguna de Uncal, a las 10 y 3/4. Este Uncal es una laguna bastantemente crecida, que ahora la tenemos a la derecha, que dista de San Lucas, como 5 leguas y 1/2. A la tarde pasamos la cañada, y anduvimos como 1 legua por dar lugar a que saliesen todas las carretas de dicha cañada, y compusiesen 7 ruedas, que se desgraciaron.

Día 9. No se caminó por la mañana, dando lugar a que se compusieran dichas ruedas. Y a la tarde caminamos como 3 leguas.

Día 10. Caminamos a la una de la tarde, porque hubo que componer varias carretas, y anduvimos cosa de 2 leguas, porque llegaron este día, muchos indios e indias e instaron a que se les diese lugar para hacer sus tratos, por cuyo motivo paramos como legua y $1 \frac{12}{2}$ del del [sic] médano del Agua.

Día 11. Caminamos a las 6 y 1/4 de la mañana, y paramos a las 12, anduvimos de 5 a 6 leguas. Y a la tarde marchamos hasta las 7, y andaríamos de 4 a 5 leguas: este día llegaron muchos indios, y nos acompañaron hasta el / f. 566/ otro día domingo.

Día 12. Marchamos a las 5 y 3/4 después de haber oído misa, pasamos la cañada larga, y al salir de ella, sucedió que Don Miguel Suarez, mató a un peón de su tropa, y al fin paramos en la ladera, porque hubo quiebras de carretas, y empezó a llover. Aquí se paró el resto del día, y se le dio sepultura al cadáver[.]

Día 13. Marchamos a las 5 y 11 minutos de la mañana, y paramos a las 10 inmediato a un médano de agua, dejando a la derecha aquella cañada, y laguna famosa que viene desde San Lucas. A la tarde marchamos, y pasamos al ponerse el sol, se andarían este día como 7 leguas, y los indios se retiraron dejándonos la noticia, que los dos blandengues se hallaban en los toldos, a quienes encargamos nos los trajesen que se les pagaría lo que pidiesen a más de regalarles 4 barriles de aguardiente.

Día 14. Marchamos a las 4 y 3/4 de la mañana, y paramos a las 10. A la tarde marchamos y paramos a las $6 \mathrm{y}^{1 / 2}$, en un médano que se halla con bastante agua, andaríamos como 7 leguas, poco más, 0 menos.

Día 15. Marchamos a las 4 y 1/2 de la mañana y a las 11 y 1/2 llegamos a la Cabeza del Buey, caminaríamos como 6 leguas, aquí se pasó el resto del día, y llegaron algunos indios, a quienes se les volvió a encargar con grande empeño, la traída de los blandengues, y de un boyerón, que dieron parte se había ido, y diciéndoles que me alcanzasen con ellos aunque fuese hasta Palantelén.

Día 16. Paramos todo el día en este lugar, con el fin de que / f. 566v/ se compusiesen las carretas, y escribir para despachar el chasque a su excelencia.

Día 17. A la tarde marchamos a las 2, y anduvimos 4 leguas, se despachó el chasque, y el reo que hizo la muerte[.]

Día 18. Marchamos a las 4 y 1/4/4 de la mañana, y paramos a las 11 . Se andarían como 5 leguas y 1/2, y fue preciso parar el resto del día, porque hubo aflojadura y quiebras de carretas, no hubo novedad alguna particular sólo que escaseó el agua pues sólo se hallaba para las gentes. 
Día 19. Marchamos a las 7 y 5 minutos después de haber oído misa, y paramos a las 10 y $1 / 2$, también éste escaseó el agua. A la tarde marchamos hasta una hora después de ser noche, se andarían este día como 8 leguas, más, que menos.

Día 20. Marchamos a las 4 y 1/1/4 de la mañana, y llegamos a la Cruz de Guerra a la una, y pasamos por los Munigotes a las 9 de la mañana: este día anduvimos de 7 a 8 leguas, paramos en dicha laguna el resto del día, para que las caballadas, y boyadas se reforzasen.

Día 21. Nos detuvimos en este mismo lugar hasta las 2 y $1 \frac{1}{2}$ de la tarde, que marchamos, y pasamos como legua y media más adelante del médano partido en donde paramos después de haber andado cuatro leguas.

Día 22. Marchamos a las 4 y 플 de la mañana /f. 567/ y llegamos a las Dos Hermanas a las 10 y 20 minutos, no obstante que hubo algunas quiebras de carretas. A las 4 de la tarde salimos, y nos aproximamos a Palantelén. Anduvimos este día de 7 a 8 leguas.

Día 23. Marchamos a las 4 de la mañana, y a las 10, y media, llegamos a Palantelén, y a la tarde caminamos cosa de legua y media. Se andarían este día, como cuatro leguas y media, se halló provista la laguna de Agua, y en este paraje que quebró una carreta enteramente que fue preciso dejarla.

Día 24[.] Llegamos al Salado a las 8 de la mañana, y no obstante de tener bastante agua, pasamos con felicidad.

A la tarde marchamos a las $4 \mathrm{y} \frac{1}{2}, \mathrm{y}$ algunas de las carretas pasaron la cañada de Chivilcoy, y otras al día siguiente, aquí hubo quiebra de algunos ejes, y rayos. Andaríamos como 4 leguas poco más, o menos.

Día 25. Nos detuvimos en esta cañada, hasta las 8 1⁄2 de la mañana dando lugar a remediar las quiebras, a cuya hora, marchamos, y paramos a las 11 del día. A la tarde marchamos, y pasamos la cañada de las Saladas, y se hizo alto de este lado de dicha cañada. Anduvimos este día 7 leguas poco más, o menos.

Día 26. Marchamos a las 4 de mañana, y pasamos la cañada del Durazno, que dio bastante trabajo por tener abundancia de agua y barro. Se paró de este lado de dicha cañada a las 11, dando lugar a que pasasen todas las carretas, y nos aproximamos a la tarde a la cañada de los Ranchos, en donde paramos, habiendo andado como 5 / f. 567v/ leguas poco más, o menos.

Día 27. Marchamos a las 3 y $3 / 4$ de la mañana pasamos la cañada de los Ranchos, la de las Pulgas, y llegamos a la guardia, a las 10 del día poco más, o menos: desde donde con acuerdo del comandante de frontera, según el orden de su excelencia se retiraron las tropas a su destino, y cada dueño de carretas se fue con ellas a su casa.

Frontera de Luján, 28 de noviembre, de 1786.

[Rúbrica] Manuel de Pinazo

\section{Transcripción № 2}

Archivo General de la Nación (AGN), Sala IX (colonial), Legajo 1-5-3, ff 704 a 710v.

Diario de Manuel Pinazo sobre la expedición a Salinas de 1787

/f. 704/ Don Manuel de Pinazo Maestre de campo General retirado de la Jurisdicción de Buenos Aires.

Habiendo sido nombrado comandante de la presente expedición a Salinas por el excelentísimo señor Marques de Loreto Virrey Gobernador, y capitán general de estas provincias por su despacho dado en el año próximo pasado, y refrendado en 20 de septiembre del presente, acudí a 
la Frontera de Luján en 2 de octubre siguiente, y allí se me presentó la tropa destinada a la expedición por el mismo señor Virrey, y sucesivamente hasta cuatro días después de emprendida la marcha las carretas de particulares; que como todo el tren, Municiones de guerra, y boca[,] etcétera[,] se expresa en la disposición siguiente.

\begin{tabular}{|c|c|c|c|c|}
\hline Cuerpos & Capitanes & Tenientes & Subtenientes & $\begin{array}{l}\text { Tropa inclusos sargentos cabos y } \\
\underline{\text { tambores }}\end{array}$ \\
\hline $\begin{array}{l}\text { De } \\
\text { Blandengues }\end{array}$ & 1 & 1 & 1 & 200 \\
\hline De Milicias & 2 & 2 & 2 & 150 \\
\hline De Pardos & 1 & $\theta$ & 1 & 50 \\
\hline Total & 4 & 3 & 4 & 400 \\
\hline
\end{tabular}

\begin{tabular}{|l|l|l|l|}
\hline & Carretas & Carretillas & Carretones \\
\hline 336 & 22 & 5 \\
\hline
\end{tabular}

Habiendo dispuesto la expedición con el siguiente orden.

Avanguardia

Mandada alternativamente por los oficiales de mayor graduación con cuarenta hombres.

$\underline{\text { Centro }}$

Al frente la artillería, y después las carretas, y en columna a su derecha 280 hombres, y a uno, y otro costado las caballadas y boyadas con 50 hombres para el arreo, y cuidado de los caballos.

$\underline{\text { Retaguardia }}$

Mandada alternativamente por los respectivos oficiales con treinta hombres. /f. 704v/

\section{Artillería}

Cuatro cañones de a libra de bala.

Municiones de Guerra

Un carro cubierto con su cerradura y llave.

Un eje herrado de respeto para ídem

Cinco esmeriles

Una tienda cañonera con dos pilares, una cumbrera, veintidós estaquillas, y dos macetillas para ídem en un cerón.

Seis atacadores con sus lanadas de a libra

Cuatro sacatrapos enastados de ídem.

Ciento veintisiete cartuchos de lanilla con pólvora, y metralla del calibre de a una en cuatro cajones. 
Treinta y tres ídem con pólvora y bala en un cajón.

Cincuenta lanzafuegos en un cajón.

Trescientos estopines para cebar en un cajón.

Cuatro mil ochocientos cartuchos para carabina del calibre de a diecinueve en cuatro cajones.

Mil doscientos ídem para fusil del calibre de a 16 en un cajón.

Cien piedras de chispa para carabina

Treinta ídem para fusil; estas dos partidas en el cajón donde van los fusiles.

Dos cavadores enastados

Cuatro botafuegos de tenasilla

Cuatro punzones con sus tapafogones

Dos Mazos de mecha.

Doce cohetes.

$\underline{\text { De Boca }}$

Seiscientas cabezas de ganado

Diez y seis quintales de vizcocho

Doce arrobas de tabaco en rama

Setenta y seisdichas de yerba.

Media fanega de sal.

Una arroba de garbanzos

Una dicha de arroz

Una dicha de azúcar

Dos barriles de vino

Un barril de aguardiente para regalar los indios /f. 705/

Una frasquera de ídem

Capilla

Todo recado de decir Misa.

Dos faroles

Ocho velas de cera

Un hostiario de hoja de lata

Un mesa.

Botiquín completo de lo más preciso en un cajón de pino

Un barril de aguardiente para la enfermería

Otro dicho de seis frascos de vino blanco para cocimientos.

En la referida disposición se emprendió la marcha del día 4 del citado octubre, y se caminó legua y media, habiendo hecho alto en el paraje llamado de las Pulgas. 
El día 9 se anduvieron 4 1⁄2 leguas, y paramos en el durazno, en donde nos mantuvimos también el día 6 siguiente.

El día 7 se caminaron $8 \frac{1}{2}$ leguas, y se hizo alto en una cañada poco distante de Chivilcoy.

El día 8 habiéndose unido ya todo el número de carretas, pasamos el Salado, que se halló lleno de agua, habiendo caminado 7 leguas.

En estos días se encontró en los campos de Chivilcoy un indio teguelchu, a quién examiné, y dijo se venía a los cristianos, porque los indios lo maltrataban. Llegó con la expedición hasta salinas, y siempre huía de los indios; pero al regreso se escapó, y no [a]pareció más.

También en este día se vieron yeguadas cimarronas sin número.

En el día 9 se caminaron 7 leguas, habiendo encontrado las lagunas de las Hermanas, como igualmente las de Palantelén[,]Chivilcoy y Durazno provistas de agua, y paramos como dos leguas adelante de dichas Hermanas.

Desde este paraje destaqué una partida de cien hombres con el Baqueano en busca de ganado.

El día 10 se caminaron 2 leguas, y fue preciso hacer alto en el médano Partido, por haberse perdido una boyada, y esperar que se buscase.

El día 11 se anduvieron 4 leguas, y se paró en la Cruz de Guerra, cuya laguna estaba bien provista de agua. / f. 705v/

En este día experimentamos una tormenta muy grande de truenos, y nos cayó mucha piedra; pero fue de poca duración.

Igualmente en este día se vieron yeguadas cimarronas que incluían un sin número de cabezas.

El día 12 se caminaron 8 leguas, habiendo pasado los Monigotes, en donde se halló muy poca agua en algunas lagunitas, pues no hay ninguna de consideración, y es un paraje muy estéril, y paramos una legua antes de llegar al Juncal, sin haber hallado agua.

El día 13 se anduvieron de 8 a 9 leguas, sin haber hallado agua, sino para la tropa, y paramos.

El día 14 se caminaron 8 leguas, sin haber hallado agua.

El día 15 se anduvieron 6 leguas, y en la cabeza del Buey, donde paramos, se encontró bastante agua, y antes de llegar a este paraje como 3 leguas, también se había encontrado una laguna con agua, aunque no la que era menester para los animales.

Días 16, y 17 se dio descanso.

En este último día llamé a todos los dueños de carretas y los hice presente, que aunque para llegar a las Salinas no faltase agua, era muy difícil encontrarla al regreso de ellas, pues habían visto por todo el camino las más famosas lagunas secas, o con muy poca agua, y que si no llovía, a más de lo que naturalmente se disipa, y consume, aunque fuera mucha más, no bastaba para la infinidad de yeguadas cimarronas, que habíamos encontrado. Que tuviesen presenta la expedición del año de [17]69 manda[da] por el Sargento Mayor Don Tomas de Benavidez, en que habiéndose experimentado igual seca a la que padecían en la actualidad, se murieron más de 1500 Bueyes, y se quemaron algunas carretas, derramando la sal, y que reflexionasen, sino obstante todo querían seguir gustosos el viaje, o volverse a sus casas.

Y habiendo la mayor parte de los referidos dueños respondido, que no obstante todo, gustosamente querían seguir el viaje, quedó determinada su continuación.

También en el mismo día volvió la Partida, que en el día 9 había destacado en busca de Ganado, y dijo no haber hallado alguno, sino unas caballadas, que pastoreaban unos cuantos indios, los 
cuales / f. 706/ luego que los avistaron, huyeron todos; pero que ni se les siguió ni hizo daño en la hacienda que guardaban.

Igualmente en el propio día despaché la partida a reconocer si había agua, y volvió con la noticia de que al sudoeste a distancia de 5 leguas había encontrado una cañada, y al pie de ella entre unos médanos mucha agua, y junto a ellos una laguna de Junco muy grande también con abundancia de agua; cuyo suelo era barro, y en dicho paraje al cacique Catuen con sus indios, que me estaba esperando, y luego recibí un recado suyo, para que marchásemos allá.

El día 18 al tiempo de marchar, se reconoció necesitaba más descanso la Boyada, y por esto se suspendió el viaje hasta el día siguiente.

En el día 19 despaché una partida a descubrir si había agua inmediato al camino, y habiéndola encontrado (aunque algo salobre) al sudoeste a media legua de él, hicimos allí alto, sin pasar a la de que se habló en el día 17, respecto a que aquella estaba distante de dicho camino 4 leguas.

En la tarde de este día vino a verme el cacique Catuen con algunos indios, todos tan sin cuidado, que manifestaban la mucha confianza, que tenían de nuestra buena fe.

En el día 20 me suplicó el referido cacique me detuviese, para que sus indios tratasen, y contratasen, como lo hicieron, comprándoles nosotros muchos caballos, mantas, y plumeros, con lo cual se retiró el cacique con sus indios.

En el día 21 se caminaron 7 leguas, y con noticia que dio la partida reconocedora, de que había agua en la lagua del Tigre, paramos en ella.

El día 22 se caminaron 7 leguas, e hicimos alto a la falda de la cañada larga por haber descubierto la partida reconocedora al norte del camino a distancia de un cuarto de legua tres lagunas de junco con agua suficiente.

Este día llegaron a verme los caciques Antonio y Guenquene acompañados de muchos indios e indias, quienes vendieron muchos caballos, ponchos, pieles y plumeros.

El día 23 pasamos la cañada larga, y se caminaron de 6 a 7 leguas sin haber encontrado agua, pues aunque se vieron muchas lagunas con ella, era salada; pero habiendo cavado a distancia de media legua del camino, se encontró muy presto buena, y la suficiente para la tropa /f. 706v/ y habiendo después la partida reconocedora avisado de dos lagunas bien provistas a igual distancia de media legua del camino, una a la derecha y otra a la izquierda de él, paramos.

El día 24 se caminaron 5 leguas, y en los primeros médanos, que encontramos, hallamos agua para la tropa, y para la mayor parte del ganado; pero habiendo caminado hacia los médanos grandes que están a la derecha del camino a distancia de un cuarto de legua, se halló agua suficiente para todos, y a la izquierda una laguna salobre, en donde en caso de necesidad podía haber bebido el ganado. El valle donde estaba esta laguna tiene muchas; pero todas saladas.

En este día se despidieron los caciques, que habían venido el día antecedente.

También en este día me enviaron los caciques Cantupi y Currutipay un recado, pidiéndome les permitiese venir con sus indios a vender caballos, lo que les concedí, y vinieron al instante con muchos indios e indias.

Este mismo día llegó Manuel Pinaso hijo del cacique Canebayon a decirme de parte del cacique Canebayon su padre, que este me estaba a 6 leguas de distancia con sus indios[.]

Igualmente vinieron los caciques Cancupi, y Anteman, y una mujer de este.

De suerte que desde la Cabeza del Buey hasta este sitio, estaba siempre el campamento lleno de infinidad de indios. 
El día 25 se caminaron 4 leguas, y paramos frente la laguna del Monte, y la partida reconocedora encontró a distancia de 3 cuartos de legua del camino a la derecha de él un médano con agua para la tropa.

El día 26 se anduvieron 9 leguas, y paramos en los Manantiales del Petiso, habiendo reconocido una laguna de Junco, llena de agua.

En este día llegó a visitarme una sobrina del cacique Anteman, acompañada por tres indios.

Desdedicho otro sitio desertó José Valor peón de las carretas de Andrés Velásquez.

El día 27 se caminaron 6 leguas, y paramos en la laguna larga, que solo tenía agua para un día, habiendo visto también secas las lagunas de los Paraguayes.

El día 28 se caminaron 4 leguas, no habiendo encontrado agua en la laguna de los Patos, en donde hicimos alto, porque el ganado no /f. 707/ podía resistir la fuerza del sol.

En este paraje mandé reforzar la avanguardia, y unida a la partida avanzada, di orden, para que reconociesen la laguna de la sal, los manantiales, y sus cercanías, y habiendo vuelto con la noticia de no haber ninguna novedad, marchamos a dicha laguna de la sal, la que encontramos enteramente seca, con admiración mía, y de cuantos la han frecuentado, pues jamás la habíamos visto en esta disposición, de suerte que siendo así que tiene más de 5 leguas, se galopaba por toda ella sobre la sal, lo mismo que por el camino.

El día 29 después de haber formado el campamento, mandé colocar la artillería en la disposición siguiente.

Un cañón a la parte del oeste sobre la barranca que da entrada al campamento, otro al este de la misma barranca, y los otros dos a la retaguardia del campamento apuntando al Norte, y formando línea con cinco esmeriles, al cuidado todos de los artilleros, sostenidos de 25 hombres, a más de continuadas rondas por fuera de dicho campamento.

Después di orden para que marchasen las boyadas, y caballadas a los manantiales, que distan de la laguna como 3 cuartos de legua, y yo también me transferí a dicho paraje con la escolta conveniente para resguardo del ganado, y despaché cinco partidas de a tres hombres. La $1^{\underline{a}}$ al sur de la laguna. La $2^{\mathrm{a}}$ al este, que es su entrada por el bajo de la barranca. La $3^{\mathrm{a}}$ al Oeste, y las dos últimas al Norte, dándoles a cada partida las señas, que debían usar, en caso de que reconociesen, o tuviesen, indicios de enemigos, y un cohete a cada partida, para que lo echasen al aire, a fin de que por los médanos altos, que hay en este paraje, no se confundiesen las señas.

También mandé poner un centinela en el médano más elevado prevenida [sic] de las mismas señas, e igualmente otro centinela en un alto inmediato al campamento, para que la repitiese.

Después de dadas todas estas disposiciones, me retiré al campamento y mandé que entrasen a cargar la sal.

En este día llegaron a visitarme varias indias, e indios, entre ellos el indio Juancho Que traía a Justo Garro, a quién dijo, que los indios Peguelchus habría [sic] como cuatro meses lo habían cautivado, cuando robaron el ganado y caballada a los pobladores del / f. 707v/ Río Negro, dándome también razón de que los indios de los caciques Catuen, y Lorenzo tenían varias cautivas y cautivos, que instaban a que los sacasen, especialmente una gallega, que llevaron de la guardia de los Ranchos. Rescaté al referido Garro, y encargué que me trajesen los demás cautivos, pues se los pagaría como quisiesen.

Como los Manantiales estaban muy escasos de agua, mandé limpiarlos, y aunque de esta suerte se logró aumentarla, no producían toda la que era menester para tan crecida boyada y caballada, 
pues la $1^{\mathrm{a}}$ ascendía a 4500 cabezas, y la otra a $4700^{50}$, y como a consecuencia de la falta de agua, escaseaban también los pastos, se deterioró mucho el ganado, aunque sin mortandad.

El día 30 no ocurrió novedad, y se continuó la carga de sal.

El día 31 se continuó la carga de sal.

En este mismo día llegó al campamento el cacique Currutipay con sus indios a vender caballos, plumeros etcétera.

Mes de noviembre

El día $1^{\circ}$ se continuó la carga de sal, y la venida de indios a vender sus efectos.

El día 2 llegaron dos hijos de los caciques Anteguan y Cariguan con varios indios rancacheles, a quienes obsequié, y pedí dijesen a sus padres me enviasen los dos cautivos, y cuatro cautivas que tenían, que se les daría por ellos cuanto quisiesen, y aunque ofrecieron volver a los tres días, no [a]parecieron.

El día 3 me envió el cacique Guenquene dos indios, avisándome de que al otro lado de la sierra había muchos indios teguelchus; y que ignoraba si venían contra mí, o contra él, y que estuviese con cuidado.

El día 4 díadel cumpleaños de nuestro Monarca mandé hacer triple salva.

El día 5 cargadas ya todas las carretas de sal, se dispusieron en el mismo orden que habían ido, para su regreso a Buenos Aires.

El día 6 se emprendió la marcha con gran trabajo, así por la deterioración del ganado, como porque el camino era de arena suelta con muchos médanos, y habiendo llegado a la laguna de los Patos, hallamos en ella, y las inmediatas suficiente agua para aquél día, en el cual avisó la retaguardia, que habían llegado 4 indios pidiendo lenguaraz para hablarnos, el que despaché al instante; pero este cuando llegó, ya habían marchado sin / f. 708/ decir cosa alguna.

El día 7 se caminaron 5 leguas.

En este día vino el cacique Currutipay, con sus indios a vender caballos, y después de obsequiado, me ofreció traerme dos cautivos muchachos, y promover, que los demás indios trajesen los cautivos que tuviesen, asegurados, que se les daría todo lo que pidiesen por su rescate.

También me dijo el mismo cacique que José Antonio Valor Peón de las carretas de Andrés Velasquez, que desertó de los manantiales del Petiso, había llegado a los toldos, diciendo, que yo al regreso de salinas había resuelto pasar a cuchillo todos los indios. Que con este motivo se tuvo junta de caciques, y convinieron, en que no se le debía dar crédito, respecto la buena fé, que en mi habían reconocido, y que desde luego se asegurase al delator para traérmelo, lo que ofreció ejecutar al camino.

El día 8 se anduvieron como 6 leguas, habiéndose roto algunas carretas, y paramos en la laguna del Juncal.

En este día llegaron muchos indios, e indias de todas parcialidades a vender sus efectos, y un aviso del cacique Catuen, de que al otro lado de la sierra Grande se hallaban muchos indios Teguelchues, unidos a otros indios de a pie, y que estuviese con cuidado, que no sabía si venían contra ellos, o contra mí.

El día 9 se caminaron 6 leguas, y acampamos en la laguna Larga, donde encontramos agua para un día.

El día 10 se anduvieron 7 leguas, y paramos en el Juncal, a cuya inmediación encontramos en una laguna agua suficiente. 
En este día vinieron muchos indios, y me trajeron los dos muchachos cautivos, que el día 7 me había ofrecido enviar el cacique Currutipay. El uno de once años, y el otro de 18, por cuyo rescate les dí cuanto pidieron.

El día 11 se caminaron 3 leguas, y paramos en un médano que se halla en medio del camino, en donde sólo se encontró agua para la gente.

El día 12 se anduvieron 7 leguas, y paramos en los médanos Grandes donde se encontró agua en abundancia.

En la jornada de este día vimos con asombro enteramente seca la famosa laguna de agua de agua salada llamada del Monte, que tiene más de 16 leguas de largo, y a la izquierda del camino como a media legua de él otra laguna con agua buena, y suficiente. / f. 708v/ También en este día llegaron muchos indios a vender ovejas y corderos.

Igualmente llegó el cacique Anteman, quién al instante se emborrachó, y de vergüenza se fue, sin verme.

Asimismo vino el cacique Guanquene con otros indios, quien antes me pidió dos hombres, y yo le di cuatro para traerme como lo hizo el peón desertor José Antonio Valor citado en el día 7.

También vino el cacique Cañeupi con sus indios a hacer trato.

El día 13 se caminaron como 2 leguas, y paramos sin encontrar agua, sino para la gente.

En este día vinieron varios indios a vender caballos etcétera.

El día 14 se anduvieron 7 leguas, y paramos inmediato a una laguna, que está a la izquierda del camino como a distancia de media legua cerca al médano del cacique Yati, en donde se encontró agua suficiente, y también habíamos en aquel día visto agua bastante en un médano chato a la derecha del camino, y como a distancia de dos tiros de fusil de él.

El día 15 se caminaron 3 leguas, y habiendo pasado la cañada larga fue menester parar para componer muchos ejes, y otras quiebras de carretas.

El día 16 se anduvieron 8 leguas, habiendo encontrado en otra cañada agua, aunque no la suficiente para todo el ganado.

El día 17 se caminaron 4 leguas, y pasamos la laguna del Tigre, que a la ida estaba seca, y ahora la encontramos con bastante agua; pero muy salada. Y la partida reconocedora como a 3 leguas distantes a la derecha del camino otras dos lagunas con abundancia de agua aunque algo salobre.

En este día llegaron a visitarme de parte de sus maridos la más joven de las mujeres del cacique Catuen, y otra del cacique Lorenzo, acompañadas de muchos indios e indias, a cuyas dos cacicas obsequié, regalándolas cuanto pude, de que quedaron muy contentas, habiendo vendido los demás indios muchos caballos.

El día 18 no se caminó por esperar dos tropas de carretas que se habían rezagado.

En este día se retiraron las cacicas con sus comitivas, y antes de marchar, las supliqué enviasen todas las cautivas, que les daría cuanto quisiesen por ellas, a que me respondió la mujer del cacique Lorenzo, que / f. 709/ fuésemos a los toldos a rescatarlas; y aunque estuve resuelto a marchar con 100 hombres, no obstante la penuria del agua, me vi prudentemente obligado a dejarlo, por lo que aconteció, y se referirá el día siguiente inmediato.

El día 19 también subsistimos acampados, y me dió parte un indio, de que al retirarse del campamento para su toldería acompañado de otro, encontraron dos soldados blandengues, quienes les convidaron con tabaco para fumar, y que con demostración de sacar fuego para encender, les apuntaron las pistolas a los pechos, y dispararon: que el otro indio cayó 
inmediatamente muerto, más que afortunadamente la pistola, que le apuntaron a él, no tenía bala; pero que los tacos, y la pólvora le habían puesto de aquella suerte, y descubriendo el pecho le vi lastimosamente quemado.

Inmediatamente le hice curar por el cirujano de la expedición, y deseoso de dar a los indios una satisfacción, cual convenía, y de castigar tal atentado, mandé formar toda la tropa, y que desmontados los blandengues, dejando los caballos, saliesen diez pasos al frente, con el fin de reconocer las dos pistolas disparadas, y venir por ellas en conocimiento de los reos; pero se encontraron ocho, con lo que se me frustró la idea.

Pregunté al indio si conocía los blandengues agresores, y respondió que sí, con lo que mandé que con pausa desfilasen todos por delante de él, para que los reconociese, y señalase; pero tampoco esta diligencia surtió efecto, pues sin embargo de haberse practicado como correspondía, dijo que no atinaba con ellos.

Satisfecho el indio de las prolijas diligencias que se habían hecho, y de la buenaacogida que en mi había encontrado: curado y regalado se retiró a su toldo, contando lo que había pasado, lo que hizo decir a su cacique Catuen, que así como había indios malos, también había cristianos malos, y que en sus excesos no tenían parte los demás, con lo cual se apaciguaron todos, sin que por eso dejase yo de estar alerta, por si ocurría alguna novedad de venganza de parte de los indios, que no manifestaron, antes si continuaron sus tratos con la misma fe, que antes.

También en este día me dijo el indio Juancho Matanza reservadamente /f. 709v/ que lo[s] indios, que estaban al otro lado de la sierra grande, estaban convocados con el cacique Lorenzo para invadir en el Zanjón partido de la Magdalena, con el fin de hacer quedar mal al cacique Catuen, y hacer sospechoso con el señor Virrey, y que convenía se lo participase yo al mismo Catuen por una carta, que él se la explicaría, y efectivamente así lo hice, y di también oportunamente aviso a su excelencia.

El día 20 caminamos 5 leguas; habiéndosenos rezagado muchas carretas por quiebras, y haberse aflojado los rayos, con cuyo motivo destaqué una gruesa escolta para su resguardo, y con las demás paramos en frente de un médano chato, que está a la izquierda del camino, e inmediato a él, y no se halló agua, sino para la gente.

El 21 mandé, que de cada dos carretas se destacase un peón, para que todos juntos cavasen en el médano, a fin de sacar agua para los animales. Empezada la faena avisó la partida reconocedora haber hallado una laguna grande abundante de agua como a 3 leguas de distancia a la derecha del camino, con lo que mandé inmediatamente cesar el trabajo de cavar en el médano, y que se llevasen a la referida laguna las caballadas y boyadas, y aunque se adelantaron las partidas, a fin de reconocer si encontraban agua, para poder emprender la marcha, no descubrieron ninguna, con lo que fue preciso guardar la misma posición los dos días siguientes.

El 22 no hubo novedad.

El día 23 despaché chasque al señor Virrey, avisando lo que ocurría, y al referido chasque se agregaron varios individuos de las carretas, para venir y llevar de sus casas al camino bueyes, y otros auxilios que necesitaban. También doblé la partida reconocedora, para que se alejase cuanto pudiese en descubrimiento de agua.

Igualmente en este día llegaron 4 indios de parte del cacique Catuen a decirme que no tuviese cuidado por la muerte del indio citado, repitiendo que así como había indios malos, también había cristianos malos.

El día 24 se caminaron 4 leguas, y paramos como una legua más delante de la Cabeza de Buey, por haberse hallado una laguna con bastante agua, aunque 4 leguas distante del camino. 
El día 25 subsistimos acampados todo el día sin alguna novedad.

El día 26 dio noticia la partida reconocedora, que en la Cruz de Guerra había agua competente para un día.

El día 27 por la tarde marchamos, y en ella, y por la noche se caminaron /f. 710/ diez leguas, y paramos el día 28 en el juncal grande si[n] haber encontrado agua.

El día 29 quedándome en el mismo campamento despaché las boyadas y caballadas a la Cruz de Guerra, a fin de que aprovechasen el agua que allí había antes que las bagualadas las bebiesen.

El día 30 se paró todo el día, y a fuerza de cavar se sacó agua para la gente, y para los caballos de monta, y recibí aviso de que la partida reconocedora había hallado una laguna abundante de agua, distante 5 leguas de la Cruz de Guerra antes de llegar a ella, como una legua corta al este del camino, pasado el médano partido, y que se habían transferido todas [las] boyadas, y caballadas a ella, porque en dicha Cruz de Guerra ya no habían encontrado más agua, que para las primeras boyadas.

$\underline{\text { Mes de Diciembre }}$

El día $1^{\circ}$ conservamos la misma situación, y di orden, para que se mantuviesen todos los animales en dicha laguna con el fin de que se restableciesen.

El día 2 subsistimos acampados, y la gente salió a campear, y mató muchos toros para comer, con lo que dí orden, para que no se diese ganado de consumo.

El día 3 subsistimos en el mismo paraje sin novedad.

El día 4 mandé traer algunas boyadas, y parte de las carretas marcharon por la tarde, y otras a las 7 de la noche, quedando las demás en el mismo campamento con la mayor fuerza de la escolta, y habiendo caminado toda la noche, paramos en la Cruz de Guerra sin encontrar gota de agua, después de haber andado 9 leguas.

Esta misma noche se prendió fuego al campo, y nos vimos en un instante cercados de fuego, y con mucho riesgo; pero mis prontas disposiciones tuvieron el éxito deseado, pues se logró apagarlo breve, aunque a fuerza de mucho trabajo.

El día 5 se cavó para dar agua a las boyadas; pero fue infructuoso el trabajo, porque como el terreno era arena, tapaba cuantos conductos se abrían, y habiendo marchado parte del día y de la noche, y caminando 6 leguas, enfrentamos a las $7 \frac{112}{2}$ de la mañana del día 6 con la referida laguna a donde se enviaron las boyadas[.]

A esta laguna le puse el nombre del Socorro de San Nicolás de Bari, por haber llegado a ella en este día. Dista del camino una legua corta /f. 710v/ a la derecha de él; tendrá de largo como dos cuadras, y las mismas de ancho. El suelo es tosca. Le sale un ramblón a modo de arroyo al Norte, que tendrá de largo una cuadra, y de ancho como 14 varas, y otro al sur con las mismas circunstancias. Está rodeada de una barranca como de 5 cuartas de alto, y solo donde salen los dichos ramblones tendrá como tres cuartas.

El agua es muy buena, y sólo al último cuando los animales la habían revuelto demasiado, se percibió algo salobre.

El día 7 por la tarde y por la noche se caminaron 5 leguas, y habiendo pasado Las Hermanas, que hallamos secas, el día 8 a las 7 1⁄2 de la mañana, paramos en Palantelén, en donde hallamos refuerzo como de 10 Bueyes de los que los dueños de las carretas habían pedido a sus casas, con los peones, que se unieron al chasque que despaché a Buenos Aires en el día 23 del pasado, como allí se dijo, y también 50 bueyes que fletó el comandante de la frontera con algunas camas, y rayos de carretas. 
El día 9 esperamos la reunión de todas las carretas, la que se verificó.

El día 10 marchamos, habiendo dado agua a las boyadas en los manantiales de Caleyan, y después pasamos el salado, que hallamos enjuto, y llegamos a Chivilcoy, de donde seguimos parte de la noche, y habiendo andado como 7 leguas, llegamos a las saladas, en donde paramos después de haber caminado por la noche como 8 leguas.

El día 11 hicimos alto en este sitio, por hallarse proveído de agua.

El día 12 dije a los dueños de las tropas de carretas, que el que quisiese adelantarse, e irse a la Frontera, podía hacerlo, con cuyo motivo se fueron muchas carretas, que llegaron a la frontera al día siguiente, y yo me mantuve en el mismo campo, habiendo reforzado la retaguardia.

El día 13 marchamos, y habiendo trasnochado y caminado 9 leguas, llegamos a dicha frontera el día 14 a las 9 de la mañana, y di orden a la tropa que se retirase a sus puestos, y los carreteros que se fuesen a sus casas.

Frontera de Lujan 14 de Diciembre de 1787

[Rúbrica] Manuel de Pinazo

\section{Transcripción № 3.}

Archivo General de la Nación (AGN), Sala IX (colonial), Legajo 13-8-17

Diario de Manuel Pinazo sobre la expedición a Salinas de 1788

/ Don Manuel de Pinazo Maestre de campo general retirado de la jurisdicción de Buenos Aires.

Habiendo sido nombrado comandante de la presente expedición a Salinas por el excelentísimo Señor Marqués de Loreto virrey gobernador, y capitán general de estas provincias con igual confianza, que en los años anteriores acudí a las [sic] frontera de Luján en 6 de octubre del presente año, y allí se presentó la tropa destinada a la expedición por el mismo señor virrey, y sucesivamente hasta cinco días después de emprendida la marcha las carretas de particulares, que como todo el tren, municiones de guerra y boca[,] etcétera[,] se expresa en la disposición siguiente

\begin{tabular}{|c|c|c|c|c|c|c|c|}
\hline Cuerpos & \multicolumn{2}{|c|}{$\underline{\text { Capitanes }}$} & tenientes & \multicolumn{2}{|c|}{ subtenientes } & \multicolumn{2}{|c|}{$\begin{array}{l}\text { Tropa inclusos } \\
\text { sargentos, } \\
\text { tambores cabos }\end{array}$} \\
\hline $\begin{array}{l}\text { De } \\
\text { blandengues }\end{array}$ & \multicolumn{2}{|l|}{2} & 1 & \multicolumn{2}{|l|}{1} & \multicolumn{2}{|l|}{200} \\
\hline De milicias & \multicolumn{2}{|l|}{2} & 2 & \multicolumn{2}{|l|}{2} & \multicolumn{2}{|l|}{146} \\
\hline \multirow[t]{2}{*}{ De pardos } & \multicolumn{2}{|l|}{1} & 1 & \multicolumn{2}{|l|}{1} & \multicolumn{2}{|l|}{36} \\
\hline & \multicolumn{2}{|l|}{5} & 4 & \multicolumn{2}{|l|}{4} & \multicolumn{2}{|l|}{382} \\
\hline & & \multicolumn{3}{|l|}{ Carretas } & \multicolumn{2}{|l|}{ carretillas } & carretones \\
\hline & & \multicolumn{3}{|l|}{246} & \multicolumn{2}{|l|}{13} & 5 \\
\hline
\end{tabular}

Habiendo dispuesto 
la expedición con el siguiente orden.

Avanguardia

Mandada alternativamente por los oficiales de mayor graduación[.]

Centro

Al frente la Artillería, y después las carretas, y en columna a su derecha 262 hombres, y a uno y otro costado las caballadas y boyadas con 50 hombres para el arreo, y cuidado de los caballos.

$\underline{\text { Retaguardia }}$

Mandada alternativamente por los respectivos / oficiales con 30 hombres.

Artillería

Cuatro cañones de a libra de bala.

Municiones de guerra

Dos carros cubiertos con su cerradura y llave[.]

Cuatro esmeriles.

Doscientos cartuchos de metralla[.]

Idem cuatro de bala rasa[.]

Cartucheras para los estopines de ídem, dos

Cuatrocientos estopines

cincuenta lanzafuegos.

cuatro guardafuegos de lata.

Cuatro Punzones.

Setenta brazadas de mecha

Cuatro atacadores con sus lanadas

Un sacatrapo.

Sotrozos de repuesto veintinueve

Un encerado.

Dos martillos de oreja.

Cuatro esmeriles con sus tragantes.

Cuatro mil cartuchos con bala para carabina en cuatro cajones.

Mil doscientos dichos para fusil en un cajón.

Trescientas piedras de chispa para carabina y pistola en un cajón.

Cien dichas para fusil.

Doce dichas para esmeriles.

doce cohetes

De boca

Dieciséis quintales de vizcocho 
Quinientas catorce cabezas de ganado

sesenta y ocho arrobas de yerba /

Un tercio de ají

Doce arrobas de tabaco en rama

Una dicha de garbanzos

una ídem de arroz

Diecisiete libras de azúcar

Un barril de vino blanco de la tierra.

Uno dicho ídem tinto

Uno dicho de aguardiente para regalar a los indios.

Una frasquera con nueve frascos de aguardiente

media fanega de sal.

Capilla

Todo recado de decir misa.

Una mesa de tijera para ídem

Dos linternas de talco

Un hostiario de hoja de lata

Cuatro velas de cera

Un toldo de campaña.

$\underline{\text { Botica }}$

Un cajón de pino compuesto de lo más preciso

Un barrilito de seis frascos de aguardiente de España para la enfermería.

Un dicho ídem de vino blanco para cocimientos.

(Nota)

Además se llevaron cien caballos del rey para tirar la artillería.

En la referida disposición se emprendió la marcha el día 9 del citado octubre, y se caminó hasta la cañada del Durazno, que dista 5 leguas de la Guardia, manteniendome en este paraje hasta el día 11 a la tarde, con el fin de que se reuniesen las carretas, que aún no habían llegado.

El mismo día 11 a la tarde se emprendió la / marcha de este lugar reunidas ya todas las carretas, y se hizo alto a las oraciones en las Saladas, habiéndose caminado cinco leguas.

El día 12 se emprendió la marcha a las siete de la mañana, y habiendo pasado Chivilcoy, paramos dos leguas antes de llegar al Salado; se andarían 9 a 10 leguas.

El día 13 se marchó a las cinco de la mañana y habiendo pasado el Salado, que llevaba bastante agua, llegamos a Palantelén, donde se hizo alto; se andarían 9 leguas.

Desde este paraje destacó el comandante una partida de 80 hombres al cargo del teniente Don Francisco Álvarez con el baqueano Eusebio Caraballo en busca de ganado por informe que le habían dado de que en aquellos campos había suficiente número de esta especie. 
El día 14 se emprendió la marcha a las cinco de la mañana, y pasando las Hermanas hicimos alto frente de la laguna del Socorro San Nicolás de Bari: Se andaría 8 leguas.

El día 15 se emprendió la marcha a las tres de la mañana; pasamos la Cruz de Guerra e hicimos alto en los Monigotes: se caminaron de 8 a 9 leguas.

El día 16 se emprendió la marcha a las doce de la noche, y nos amaneció en el Juncal de los Jagües, y después de haber dado un rato de descanso a la boyada, marchamos hasta la tarde, que se hizo alto en un paraje sin agua para los animales, habiendo caminado como 12 leguas. /

El día 17 marchamos a las dos de la mañana, y pasamos una laguna que está a la derecha del camino e inmediata a él, y a la tarde hicimos ato a las $5 \frac{1}{2}$ en la Cabeza del Buey: Se caminaron 8 a 9 leguas.

El día 18 se emprendió la marcha a las cinco de la mañana, y pasando el Médano del cacique Catuen y dos lagunas de buen porte, que están a la izquierda del camino, y muy cerca de él, se despachó de chasque a un indio llamado Juancho (que salió de la guardia de Luján con la expedición) al cacique Catruen para que saliese al camino, trajese los cautivos que tuviese, y mandase aviso a los demás caciques, hiciesen los mismo: Este día se hizo alto en frente de un médano que está a la derecha del camino; se caminaron 6 leguas.

Este mismo día llegaron al campo ocho indios con tres indias de la parcialidad del citado cacique Catuen a vender caballos y pieles, donde se mantuvieron hasta el día siguiente.

El día 19 se emprendió la marcha a las siete de la mañana, y se hizo alto a la tarde en un médano que está a la derecha del camino con agua suficiente para todo el tren; se caminaron de 4 a 5 leguas.

El día 20 marchamos a las doce de la noche, y se hizo alto a las diez del día para dar algún descanso a la boyada, se volvió a caminar a las tres de la tarde, pasando la cañada larga, y se acampó entre unos médanos que a la derecha del camino están tres, y uno a la izquierda, todos provistos de agua: se andarían 10 a 11 leguas.

Este mismo día llegó el teniente Don Francisco Álvarez con su partida sin haber encontrado ganado alguno, y si / muchos toros.

También en este día, vinieron porción de indios e indias al trato, y se mantuvieron hasta el día siguiente[.]

El día 21 se paró todo el día en este lugar, por haber hecho chasque el cacique Catuen, diciendo enviaba una de sus mujeres en su lugar por hallarse lastimado de una rodada de un caballo, con la que vinieron considerable porción de indios e indias, trayendo muchos caballos, plumeros, cueros de venado, y otras pieles, riendas, y lazos para vender.

El 22 se paró todo el día a instancias de dicha cacica, y llegó el cacique Güanquenecul con porción de indios e indas al trato, trayendo bastantes caballos, y algunas mulas: se mantuvieron todos hasta el día siguiente.

El día 23 se rompió la marcha a las cinco y media de la mañana; se pasaron los médanos colorados, que están a la derecha del camino, y no lejos de él. A la tarde hicimos alto en un valle que tiene un médano al frente; se andarían 7 leguas.

Este día se retiró el cacique Güanquene, con sus indios; quedándose la cacique en el campo con los suyos, y llegaron otros del cacique Curritipay.

El día 24 se emprendió la marcha las cuatro de la mañana, y se pasó el monte que está en la costa de la laguna de este nombre, como así mismo el médano del Agua, y la laguna del Juncal, y a la 
tarde se hizo alto frente de unos médanos / y lagunas de Agua, que se encontraron en un Bañado: se caminarían ocho leguas.

El día 25 marchamos a las tres y media de la mañana, pasando la laguna de los Paragüayes, laguna Larga, y cerca de oraciones se hizo alto en el principio de la cañada, que remata en la laguna de los Patos: se andarían 8 leguas[.]

Este día llegaron los caciques Canevayon, y Curriripay con porción de indios e indias a vender sus efectos.

El día 26 se emprendió la marcha a las tres de la mañana, y se paró en la laguna de los Patos, en cuyo paraje se hizo alto, y reforzando la avanguardia, dio el comandante orden, para que se reconociese la laguna de la Sal, los manantiales, y sus cercanías, y habiendo vuelto con la noticia de no haber novedad, marchamos a dicha laguna de la Sal, llegando a ella a las cinco y media de la tarde. Nos acompañó hasta aquí el cacique Currutipay con cuatro indios más, hallándose llena de agua, donde se formó el campamento: se andaría 7 leguas.

El día 27 pasó el comandante a los Manantiales con escolta suficiente para boyadas, y caballadas; dio las órdenes que se debían observar, e instruyó al oficial de todo lo que debía practicar; mandó poner las centinelas en los médanos más encumbrados, y despachó tres partidas una al noroeste, otra hacia los montes, y la otra al este, dándoles a cada partida las señas que debían usar en caso que reconociesen, o tuviesen indicios de enemigos, a cuyo fin llevó un cohete cada una / para que lo echasen al aire, para que por motivo de los médanos altos que hay en este paraje no se confundiesen las señas.

A su regreso al campamento mandó colocar la artillería en la disposición siguiente.

Un cañón a la parte del oeste sobre la barranca, que da entrada al campamento; otro al este de la misma barranca, y los otros dos a la retaguardia del mismo campamento, apuntando al norte, y formando línea con cuatro esmeriles al cuidado todos de los artilleros sostenidos de veinticinco hombres a más de continuadas rondas por fuera de dicho campamento.

Dadas todas estas disposiciones, se mandó entrasen a sacar la sal.

En este día [se] retiró el cacique Curritipay.

El día 28 siguieron sacando sal, y llegaron los caciques Paynetu, y Toro, el primero con 27 indios, y 11 indias; el segundo con 18 indios y 5 indias, trayendo a vender muchos caballos y pieles, y se mantuvieron hasta el día siguiente.

La noche de este, sin duda por causa de los tigres o leones hubo una gran disparada de caballos, y ganado del consumo; se recogió al día siguiente lo que se pudo de este último género, logrando encontrar toda la caballada.

El día 29 se ejercitó la gente en su trabajo sin haber ocurrido novedad más que haber / llegado el cacique Catumida con varios indios, y otros de la parcialidad del cacique Antuan, de los cuales conoció Don Blas Pedrosa dos que tenían dos cautivas y aunque se les reconvino por ellas $1^{\mathrm{a}} 2^{\mathrm{a}}$ y $3^{\mathrm{a}}$ vez, no quisieron contestar, sin embargo de ofrecerles todo lo que quisiesen por su rescate: pero últimamente por la autoridad y ofertas del comandante las trajeron, y se les dio lo que pidieron por ellas.

Estas dos cautivas son hermanas, y ambas de la jurisdicción de Córdoba, la una nombrada María Juliana Serrano, de edad de 16 años, y la otra María Manuela de edad de 5 años.

El día 30 prosiguió la gente en la saca de la sal, y se retiraron algunos indios, que habían quedado en el campo con el cacique Catumilá. 
El día 31 se ejercitó la gente en su trabajo, y llegaron los cacique Painegüen, y Curral, y los indios del cacique Anteman, trayendo porción de caballos, pieles, y plumeros para vender. Entre los indios que vinieron con el cacique Paneigüen conoció el citado Pedrosa dos que tenían una cautiva, y un cautivo con los que se practicó la misma diligencia que con los antecedentes, en cuya virtud trajeron a Juana María Cabrera natural de la jurisdicción de Córdoba, de edad de 30 años poco más o menos con una hijita de dos años, la cual se bautizó, y a Fermín Quiroga de 16 años natural de la Punta de San Luis de Loyola, y se les dio a los indios todo lo que por ellos pidieron.

El día $1^{\circ}$ de noviembre continuó la gente en sacar sal, y llegó el cacique Santiago con siete indios y cuatro indias a vender caballos, pieles y plumeros, y se reti / raron todos los demás indios a excepción de estos.

El día 2 siguió la gente en el trabajo, y llegó el cacique Epucerre con 7 indios y 3 indias, y otros indios particulares de los que asisten de las Salinas para adentro; a uno de estos el nominado Pedrosa conoció e informó tenía una cautiva, con él fue preciso practicar la misma diligencia, que con los anteriores, la que mandó traer, y es Antonia Jayme natural de la jurisdicción de Córdoba, de edad de 28 años con un hijito de siete meses, que también se bautizó, y pagándole lo que pidió por su rescate, se fue con todos los demás, a excepción de uno que se quedó, y propuso venir a Buenos Aires, y hacerse cristiano, y con efecto vino.

El día 3, llegó asimismo porción de indios de las mismas parcialidades a vender caballos, cojinillos, plumeros y pieles, y se mantuvieron hasta el día siguiente.

El día 4 día del cumpleaños de nuestro monarca se hizo trip[1]e salva.

Este día salieron las carretas todas ya cargadas a ponerse en ala en sus respectivos caminos para su regreso a Buenos Aires.

El día 5 se emprendió la marcha a las cuatro de la mañana, y a las 11 se llegó a la laguna de los Patos, donde se hizo alto, habiendo caminado tres leguas.

El día 6 se puso la tropa en marcha a las 5 de la mañana, y a las 10 se hizo alto en la ladera de una cañada que tiene diversas lagunas a la derecha del camino todas de agua dulce: a las tres de la tarde se volvió a machar, y se paró, en donde remata la cañada / que sale de la laguna de los Patos: se caminó de 7 a 8 leguas.

El día 7 se marchó a las tres de la mañana, y a las ocho y media llegamos a la laguna de los Paragüayes, en donde se hallaron cuatro indios con dos indias, que venían a vender caballos, mantas, cueros de venado, y plumeros. Aquí se paró el resto del día: se andarían 4 leguas.

El día 8 se emprendió la marcha a las $3 \frac{1}{2}$ de la mañana, y a las $9 \frac{1 / 4}{4}$ se hizo alto, como 2 leguas antes de llegar a la primer[a] laguna del Junco. A la tarde marchamos, y a las 5 se paró en dicha laguna: se andarían 8 leguas.

Este día llegaron 60 indios y 18 indias, entre los cuales volvió el cacique Lepilá; vendieron muchos caballos, y algunas mulas, manteniéndose en el campo con los anteriores.

El día 9 permanecimos en este mismo sitio para componer varias carretas, que se habían descompuesto.

Este día llegó [por] segunda vez el cacique Canevayon con varios indios, y entre ellos uno llamado Tripan casado con una cautiva llamada Francisca Bengolea, a quién conoció Don Blas Pedrosa. Con este aviso se requirió al indio, para que la entregase, y habiéndose practicado iguales diligencias, que para las demás, se despachó un hermano de ella (que iba en la expedición) acompañado de tres indios a los toldos, y el día siguiente la trajeron, y se le dio al indio cuanto pidió por su rescate. Dicha cautiva es de la jurisdicción de Córdoba, y de edad de 26 años. 
El día 10 fue preciso detenerse en el mismo lugar por motivo de dicho rescate.

El día 11 se retiraron todos los indios, y a las 4 de las tarde marchamos hasta media noche: se andarían 9 leguas.

El día 12 se emprendió la marcha a las 6 de la mañana y se hizo alto a las once en un médano de mucha agua que se halla a la izquierda del camino a distancia de una cuadra, y tirando al norte se halla otro médano / chato de mucha agua, y a la derecha una cañada con diversas lagunas de agua dulce. A las tres de la tarde se volvió a marchar, y se paró frente de un médano que está a la izquierda del camino, e inmediato a él donde se pasó la noche: se andarían 8 leguas.

Este día llegó [por] $2^{\mathrm{a}}$ vez el cacique Santiago con porción de indios e indias a vender sus efectos; igualmente llegaron varios indios de Catuen, y con ellos uno que enviaba de chasque dicho Catuen al comandante solicitando informarse cómo se habían portado los indios de adentro, y que le esperaba 8 leguas más adelante[.]

El día 13 se hizo alto en este mismo lugar hasta las oraciones, que caminaron las carretas y escolta al cargo del capitán Don Antonio Olavarría, por haberse quedado el comandante con una partida de 50 hombres mandados por el aferez de blandengues Don Manuel Lizarasu con el fin de aguardar al indio marido de la cautiva Bengolea, que prometió salir a este paraje con dos hijos, y venirse él igualmente a hacerse cristiano.

El día 14 después de esperar el comandante al indio Tripan con sus hijos hasta las oraciones, viendo no [a]parecía se puso en marcha, quedándose el cacique Santiago con sus indios, y a la media noche se incorporó con la tropa en el sitio donde aguardaba el cacique Catuen, que distaría 8 leguas poco más o menos, a quién encontró en el campo con porción de indios e indias, que habían traído muchos caballos a vender: obsequio el comandante a este cacique y su mujer, y a instancias suyas, y por complacerlo, se hizo alto todo este día.

La noche del 15 se emprendió la marcha a las oraciones, y caminando toda ella al amanecer se llegó a la Cabeza del Buey, quedándose el cacique Catuen en aquel sitio con todos sus indios: se andarían 9 leguas. /

El día 16 se hizo alto todo el día en este paraje, y se despachó chasque al excelentísimo señor virrey, dando parte a su excelencia del regreso de la expedición.

Este día llegaron porción de indios con Juancho Matanza de la parcialidad del cacique Lorenzo, y el cacique Toro mandó a su hijo con 20 indios con recado al comandante porque deseaba saber cómo lo habían tratado los indios de adentro, y si había habido alguna novedad.

El día 17 se puso la tropa en marcha a las 5 de la tarde, habiendo caminado hasta la una de la noche, que se hizo alto; se caminarían 8 leguas, habiéndose retirado los indios al tiempo de marchar.

El día 18 se emprendió la marcha a las $6 \frac{1 / 2}{2}$ de la mañana hasta las 11 , y a la tarde a cosa de las $2 \frac{1 / 2}{2}$ se caminó hasta después de las oraciones, haciendo alto como tres leguas antes de llegar al segundo Juancal: se andarían 7 leguas.

El día 19 se puso la tropa en marcha al salir la luna, y pasando los Monigotes, a la una de la tarde se llegó a la Cruz de Guerra: se caminarían de 11 a 12 leguas.

El día 20 se emprendió la marcha a las $2 \frac{1}{2}$ de la tarde, y se caminó hasta las oraciones, que se paró para dar algún descanso a los animales, y al salir la luna, se volvió a marchar hasta las 7 1/2 de la mañana que llegamos a las dos Hermanas, (habiendo pasado la laguna del Socorro de San Nicolás de Bari) en donde se hizo alto: se caminarían 8 leguas. 
El día 21 se caminó a las tres de la tarde, llegando a las oraciones a Palantelén, que dista de dichas Hermanas 4 leguas.

El día 22 se emprendió la marcha a las 4 de la mañana, y se llegó al Salado a las 11 del día, donde se hizo / alto; el que no se pasó con el fin de buscar el mejor vado para el paso de las carretas: se andarían 5 leguas.

Esta noche desertaron las cautivas Francisca Bengolea y Antonia Jayme con un hijito de siete meses, que se habían rescatado: luego que dieron parte al comandante destacó cuatro partidas en su busca, mandando otra a la retaguardia del camino, que se avanzase hasta los Monigotes, que distan del Salado 24 leguas, para que volviendo por el mismo camino, que se había traído, y abiertos en ala, viniesen registrando el campo.

El día 23 se paró todo el día en solicitud de dichas cautivas.

El día 24 se pasó el Salado, y Chivilcoy, parando a las doce tres leguas más delante de este lugar, y a las dos de la tarde se volvió a poner en marcha la tropa, y se llegó a las Saladas: se andarían 11 leguas.

Este día llegaron las cautivas, que logró encontrarlas la partida arriba dicha.

El día 25 se emprendió la marcha a las 5 de la mañana; se pasó la cañada de los Ranchos, y a las 5 de la tarde se llegó a la guardia de Luján, habiendo caminado 9 leguas, donde el comandante dio orden a la tropa, para que se retirase a sus puestos, y a los dueños de las carretas a sus casas, respecto de no haberse dado providencia por los disputados para recoger la fanega de sal, que los individuos de dicha expedición deben pagar de cada carreta. Frontera de Luján 25 de noviembre de 1788[.]

[Rúbrica] Manuel de Pinazo

\section{Transcripción $\mathrm{n}^{\circ} \mathbf{4}$}

Archivo General de la Nación (AGN), Sala IX (colonial), Legajo 13-8-17

"Relación de los cautivos cristianos que se hallaron esclavos, de los indios infieles, y rescaté de orden del Excelentísimo Señor Marqués de Loreto. Virrey, y capitán general de estas provincias en las tres expediciones, a Salinas ejecutadas en los años de [17]86[,] [17]87 y [17]88. Y de que tuvo a bien el mismo Señor Excelentísimo confiarme el mando.

Número de cautivos rescatados

1. Año de [17]86. Don Blas Pedrosa, natural de la Coruña de edad de 24 años.

1. Martina Villagra, de edad de 40 años.

1. María Rosa, de edad de 26[,] ambas naturales del Río Cuarto Jurisdicción de Córdoba del Tucumán.

1. Antonio Negro esclavo de Don Franciso Ambelarde, residente en esta ciudad.

\section{Año de [17]87}

1. Pascual Garro, de edad de 24 años, natural de Santiago del Estero

5 /

5

1. Martín Juares, de edad de 18 años natural de la punta de San Luis de Loyola.

1. Juan Thomas, de edad de 20 años. 
1. Felipe Morales, de edad de once años ambos naturales de esta jurisdicción.

Año [17]88.

1. María Francisca Mengolea [sic], de 26 años

1. María Juliana Serrano de 16 años

1. María Manuela Serrano de 5 años

2. Juana María Cabrera de 30 años con una hija de 2 años la cual se bautizó luego que la rescaté, y se le puso María Man[ue]la

2. Antonia Jaime, de edad de 28 años con un hijo de 7 meses. quién también se bautizó, después que lo rescaté. y se le puso por nombre Manuel Antonio. Todos de la jurisdicción de Córdoba.

1. Fermín Quiroga de 16 años. Natural de la Punta de San Luis.

16

$\underline{\text { Nota }}$

Un indio de nación ranquel, de edad de 22 años que voluntariamente me ha seguido, con el fin de recibir el agua del bautismo el cual se está instruyendo en doctrina cristiana para recibirle"

[Rúbrica] Manuel de Pinazo

\section{BIBLIOGRAPHY}

Alemano, M. (2015). La prisión de Toroñan. Conflicto, poder y “araucanización” en la frontera pampeana (1770-1780). TEFROS, XIII (2), 27-55.

Benedetti, A. (2014). Espacios fronterizos del sur sudamericano. Propuesta de un modelo conceptual para su estudio. Estudios fronterizos, XV (29), 11-47.

Boccara, G. (2005). Génesis y estructura de los complejos fronterizos euro-indígenas. Repensando los márgenes americanos a partir (y más allá) de la obra de Nathan Wachtel. Memoria Americana, XIII, 21-52.

Carbonari, M. (2016). “(...) por haver ido yo distraida en traje de hombre”. Historia de la cautiva Francisca Bengolea en la frontera colonial del río Cuarto (Córdoba). COORDENADAS. Revista de Historia local y regional, III (2), 116-137.

Carlón, F. (2010). Liderazgos y organizaciones sociopolíticas indígenas en Pampa y Patagonia norte durante el siglo XVIII. Una reconstrucción a partir de los vínculos interétnicos en la frontera de Buenos Aires. Revista Colombiana de Antropología, XLVI (2), 435-464.

Carlón, F. (2014). Una vuelta de tuerca más: repensando los malones en la frontera de Buenos Aires durante el siglo XVIII. TEFROS, XXII (1), 26-49.

Curtoni, R. (2007). Análisis e interpretación de las rastrilladas indígenas del sector centro-este de la provincia de La Pampa. Revista de Arqueología Histórica de Argentina y Latinoamérica, (1), 65-92. 
Enrique, L. (2015). Paisajes coloniales en las fuentes escritas: una propuesta para re-pensarlos mediante la idea de "nodos territoriales". En Jensen, S; Pasquare, A. y Di Gresia, L. A. (Eds.), Fuentes y archivos para una nueva Historia socio-cultural, (pp. 139-148). Bahía Blanca: Hemisferio Derecho.

Enrique, L. (2016). Tras los pasos de un pionero: el paisaje de la "frontera sur" a través de la mirada de Pablo Zizur a fines del siglo XVIII. TEFROS, IV (2), 6-40.

Enrique, L. y Vollweiler, S. (2016). El camino a (las) Salinas (Grandes): configuraciones de un recorrido hispano en territorios indígenas durante el periodo colonial. En III Jornadas de la Red Fronteras Coloniales-Republicanas y Estratégicas Interétnicas en América del Sur. Programa de Estudios Históricos y Antropológicos Americanos. Lujan: Departamento de Ciencias Sociales, Universidad de Luján

Levaggi, A. (2000). Paz en la frontera. Historia de las relaciones diplomáticas con las comunidades indígenas en la Argentina (siglos XVI-XIX). Buenos Aires: Universidad del Museo Social Argentino.

Mandrini, R. (2006). Desventuras y venturas de un gallego en el Buenos Aires de fines de la colonia. Don Blas Pedrosa. En Mandrini, R. (Ed.), Vivir entre dos mundos. Conflicto y convivencia en las fronteras del sur de la Argentina. Siglos XVIII y XIX, (pp. 43-72). Buenos Aires: Taurus.

Martínez Sierra, R. (1975). El mapa de las Pampas. Buenos Aires: Ministerio del Interior. 2 tomos. Nacuzzi, L. (2013). Diarios, informes, cartas y relatos de las expediciones a las Salinas Grandes, siglos XVIII-XIX. Corpus, Archivos virtuales de la alteridad americana, [online] III (2). Disponible en https://corpusarchivos.revues.org/558.

Nacuzzi, L. (2014a). Los caciques amigos y los espacios de la frontera sur de Buenos Aires en el Siglo XVIII. TEFROS [online], XII (2), 103-139. Disponible en http://www.hum.unrc.edu.ar/ojs/ index.php/tefros/article/view/291/272.

Nacuzzi, L. (2014b). Los grupos étnicos y sus territorios en las fronteras del río Salado de Buenos Aires (siglo XVIII). Población \& Sociedad, XXI (2), 49-92

Nacuzzi, L. (2018). Cartas desde los bordes de la tierra adentro. En L. Nacuzzi (coord.), Entre los datos y los formatos: indicios para la historia indígena de las fronteras en los archivos coloniales, (pp. 204-223). Buenos Aires: Centro de Antropología Social-IDES.

Nacuzzi, L., Enrique, L. y Vollweiler, S. (2018). Diarios de operaciones de las expediciones hacia la tierra adentro. En Nacuzzi, L. (Coord.), Entre los datos y los formatos: indicios para la historia indígena de las fronteras en los archivos coloniales, (pp. 69-115). Buenos Aires: Centro de Antropología SocialIDES.

Nacuzzi, L. y Tourres, L. (2018). Acuerdos del cabildo de Buenos Aires. En Nacuzzi, L. (Coord.), Entre los datos y los formatos: indicios para la historia indígena de las fronteras en los archivos coloniales, (pp. 29-68). Buenos Aires: Centro de Antropología Social-IDES.

Nacuzzi, L. y Vollweiler, S. (2017). Espacialidades de la frontera colonial: de los fortines a la tierra adentro. Ponencia presentada en las XVI Jornadas Interescuelas. Mar del Plata, Argentina. [Manuscrito en prensa].

Néspolo, E. (2012). Resistencia y complementariedad, gobernar en Buenos Aires. Luján en el siglo XVIII: un espacio políticamente concertado. Villa Rosa: Escaramujo.

Pérez Zavala, G. y Tamagnini, M. (2012). Dinámica territorial y poblacional en el Virreinato del Río de la Plata: indígenas y cristianos en la frontera sur de la gobernación intendencia de Córdoba del Tucumán, 1779-1804. Fronteras de la Historia, XVII (1), 195-225. 
Pratt, M. (2011 [1992]). Ojos imperiales. Literatura de viajes y transculturación. Buenos Aires: Fondo de Cultura Económica.

Raffestin, C (2011 [1980]). Capítulo 1. ¿Qué es el territorio? En Por una geografía del poder, (pp. 102-115). México: Colegio de Michoacán.

Roulet, F (2006). Fronteras de papel. El periplo semántico de una palabra en la documentación relativa a la frontera sur rioplatense de los siglos XVIII y XIX. TEFROS [en línea], IV (2). Disponible en http://www.unrc.edu.ar/publicar/tefros/revista/v4n2p06/paquetes/roulet.pdf.

Roulet, F. (2018). Violencia indígena en el Río de la Plata durante el período colonial temprano: un intento de explicación. Nuevo Mundo Mundos Nuevos [online]. Disponible en: http:// journals.openedition.org/nuevomundo/72018

Taruselli, G. (2005-2006). Las expediciones a Salinas: caravanas en la pampa colonial. El abastecimiento de sal a Buenos Aires (siglos XVII y XVIII). Quinto Sol, IX (10), 125-149.

Zizur, P. (1972). Diario de una expedición a Salinas emprendida por orden del Marqués de Loreto Virrey de Buenos Aires en 1786 por Don Pablo Zizur Alferez de fragata, y primer piloto de la real armada. En De Angelis, P. (Coord.), COD, tomo VIII A. Buenos Aires: Editorial Plus Ultra.

\section{NOTES}

1. Las Salinas Grandes se encuentran aproximadamente a 600 kilómetros de la ciudad de Buenos Aires en dirección sudoeste.

2. Pinazo fue un destacado comerciante y miliciano de la frontera sur. Fue nombrado sargento mayor de todas las compañías de milicias de la caballería del pago de Luján en 1762, participó del Cabildo entre 1765 y 1766 y fue designado maestre de campo en 1772, cargo que continuó ocupando en 1776 junto con el de comandante general de fronteras. Asimismo, fue pulpero y propietario de campos y desempeñó otras actividades económicas como el transporte y comercio de madera y leña (Néspolo 2012). Según Taruselli (2005-2006), en 1760 ya había sido comandante de una expedición a Salinas.

3. Las fuentes aquí presentadas se encuentran en la sala IX del Archivo General de la Nación (en adelante AGN). El diario de 1786 está localizado en el legajo 19-3-5, el de 1787 en el legajo 1-5-3 y el diario de la expedición de 1788 así como el documento con la información de los cautivos rescatados se encuentran en el legajo 13-8-17.

4. En los Acuerdos del Cabildo de Buenos Aires se encuentra registrado el hallazgo de las Salinas, la modalidad que adquiriría la recolección de recurso y el impuesto que cobraría la ciudad. Además, hay reiteradas discusiones en torno a la explotación de las Salinas: si eran de uso común o si serían explotadas por privados (Nacuzzi y Tourres 2018).

5. A partir de un análisis de los casos de violencia presentados en las fuentes, Roulet (2018) sostiene que la región bonaerense fue relativamente segura para los pobladores de la colonia durante el siglo XVII ya que las agresiones indígenas se incrementaron recién a principios del siglo XVIII y fueron adquiriendo características diferentes en relación con la violencia colonial a la que respondieron durante décadas. Promediando el siglo XVIII, además de las "avanzadas" indígenas hacia los pagos fronterizos conocidos como malones, se produjeron una serie de "enfrentamientos o conflictos intertribales e interétnicos" mientras continuaron los "vínculos de intercambio, amistad y alianza" (Carlón 2014, p. 30). Para la política borbónica de tratados de paz con los diversos caciques de la región, se puede consultar Levaggi (2000).

6. Copia de carta de don Francisco de Paula Sanz al marqués de Loreto. Buenos Aires, 18 de julio de 1786. AGN, IX, 19-3-5. 
7. La participación de particulares en las incursiones promovía la valentía y el honor de los individuos en el contexto en el que vivían y las autoridades tenían especial interés en este hecho, como lo demuestran las órdenes que recibió Pinazo en 1787 cuando le indicaron que las expediciones servirían para "restituir a nuestra gente el crédito de valor, y fuerza que los infieles habían con todo perdido y debilitado". (Borrador de carta para Manuel Pinazo. Buenos Aires, 20 de septiembre de 1787. AGN, sala IX, legajo 1-5-3).

8. Diario de Manuel Pinazo sobre la expedición a Salinas del año 1786. Frontera de Luján, 28 de noviembre de 1786. AGN, sala IX, legajo 19-3-5.

9. Para un análisis de los diarios de viaje de 1781 al Fuerte de Nuestra Señora del Carmen (actual provincia de Buenos Aires), de 1786 a las Salinas Grandes y de los registros cartográficos de esta última expedición, ver Enrique (2016).

10. "Instrucciones al piloto Pablo Zizur a que se hace en referencia en el acuerdo antecedente". Acuerdo del Cabildo de Buenos Aires del 11 de octubre de 1786, serie III, tomo VIII, libro XLVIII, pp. 180-182.

11. Zizur, P. (1972). "Diario de una expedición a Salinas emprendida por orden del Marqués de Loreto Virrey de Buenos Aires en 1786 por Don Pablo Zizur Alferez de fragata, y primer piloto de la real armada". En De Angelis (Coord.), COD, tomo VIII A. Buenos Aires: Editorial Plus Ultra.

12. "Instrucciones al piloto Pablo Zizur a que se hace en referencia en el acuerdo antecedente". Acuerdo del Cabildo de Buenos Aires del 11 de octubre de 1786, serie III, tomo VIII, libro XLVIII, pp. 180-182.

13. Las escasas menciones a los grupos indígenas en el diario de Zizur se debían al objetivo que tenía el piloto para confeccionar su escrito en esta ocasión y no a su desconocimiento de los grupos. Zizur había realizado expediciones unos años antes y había relatado los contactos con los grupos indígenas, como puede observarse en su diario de 1781.

14. "Expedición a Salinas". Buenos Aires, 19 de julio de 1786. "Nota". Buenos Aires, 20 de septiembre de 1787. AGN, sala IX, legajo 1-5-3.

15. Borrador de carta para Manuel Pinazo. Buenos Aires, 20 de septiembre de 1787. AGN, sala IX, legajo 1-5-3.

16. Diario de Manuel Pinazo sobre la expedición de Salinas del año 1787. Frontera de Luján, 14 de diciembre 1787. AGN, sala IX, legajo 1-5-3.

17. Carta de Manuel Pinazo al Marqués de Loreto. Campo inmediato a la Cabeza del Buey, 23 de noviembre de 1787. AGN, sala IX, legajo 1-5-3.

18. Diario de Manuel Pinazo sobre la expedición de Salinas del año 1788. Frontera de Luján, 25 de noviembre de 1788. AGN, sala IX, legajo 13-8-17.

19. Diario de Manuel Pinazo sobre la expedición de Salinas del año 1788. Frontera de Luján, 25 de noviembre de 1788. AGN, sala IX, legajo 13-8-17.

20. En otro lugar hemos señalado la importancia de algunos parajes que se fueron cargando de significados para los sujetos que realizaban determinadas acciones en ellos como fue el caso de Cabeza del Buey (Nacuzzi, Enrique y Vollweiler, 2018).

21. Carta de Manuel Pinazo al Marqués de Loreto. Cabeza del Buey, 16 de noviembre de 1788. AGN, sala IX, legajo 13-8-17.

22. "Relación de los cautivos cristianos que se hallaron esclavos, de los indios infieles" de los años 1786, 1787 y 1788 firmado por Manuel Pinazo. AGN, sala IX, legajo 13-8-17.

23. Taruselli (2005-2006) ha estudiado a los participantes de las expediciones (carreteros, peones y vivanderos) y la conformación de la escolta (milicias y ejército) atendiendo a su procedencia y a la relación que se establecía entre ellos.

24. Los párrafos que describen la orden de la comitiva son iguales en los tres diarios a excepción de algunos signos de puntuación y a la escritura de los números. La vanguardia estuvo conformada de igual manera en los tres viajes con la excepción de que en 1786 y 1787 los oficiales de mayor graduación estaban acompañados por cuarenta hombres que no fueron mencionados 
en 1788, el centro tuvo una diferencia en la cantidad de hombres (280 en 1786 y 1787 y 262 en 1788) mientras que la retaguardia fue la misma en los tres diarios. Ver Transcripciones № 1, 2 y 3. 25. Para ese entonces, además de haber conducido expediciones hacia Salinas, Pinazo contaba con una larga trayectoria en la frontera sur de Buenos Aires que le había proporcionado amplios conocimientos sobre la territorialidad de los caciques y sus parcialidades. Por ejemplo, en agosto de 1774 tras la prisión del cacique Toroñan y su posterior reclamo por parte de sus hijos, organizó una expedición punitiva para lo cual distinguió "a las parcialidades 'aliadas y confederadas' de las 'enemigas' según se encontraran, respectivamente, al sur o al norte del camino que conducía a Salinas Grandes" (Alemano 2015, p. 32, cursiva en el original).

26. Diario de Manuel Pinazo sobre la expedición a Salinas del año 1786. Frontera de Luján, 28 de noviembre de 1786. AGN, sala IX, legajo 19-3-5.

27. Cabe destacar sobre este aspecto que los párrafos de los tres diarios de Pinazo aquí analizados en los cuales describió cómo colocó la artillería en torno a la laguna de la Sal son muy similares. La diferencia más notoria entre ellos es la utilización de signos de puntuación -algunas comas que fueron ubicadas en distintos sitios en los tres diarios- y, mientras que en 1786 y 1787 había colocado cinco esmeriles, en 1788 fueron cuatro. La repetición de las oraciones, a excepción de los signos de puntuación y de unas escasas palabras, es una característica de este tipo de fuente documental. En otro trabajo hemos analizado los diarios de operaciones acerca de las expediciones en la tierra adentro y hemos sostenido que, debido a la propia dinámica de las incursiones, los escritos fueron pasados en limpio antes de ser entregados (Nacuzzi, Enrique y Vollweiler 2018).

28. Al estudiar el sistema de caminos indígenas del siglo XIX en el área centro-este de la actual provincia de La Pampa, Curtoni (2007) observó que las rastrilladas, además de conformar un sistema de traslado de ganado, pueden interpretarse en relación con una cosmovisión que fue expresada en el paisaje.

29. Diario de Manuel Pinazo sobre la expedición de Salinas del año 1787. Frontera de Luján, 14 de diciembre 1787. AGN, sala IX, legajo 1-5-3.

30. Diario de Manuel Pinazo sobre la expedición de Salinas del año 1788. Frontera de Luján, 25 de noviembre de 1788. AGN, sala IX, legajo 13-8-17.

31. En 1788 era el tercer año consecutivo en el que Pinazo comandaba el viaje hacia Salinas por lo que podría haber reconocido la laguna que bautizó el año precedente. Otra opción podría ser que, una vez finalizada la incursión, al confeccionar el nuevo diario observara el del año anterior por lo que podría haber completado el nombre de la laguna por la que habían pasado sin haberla reconocido en el momento.

32. Diario de Manuel Pinazo sobre la expedición de Salinas del año 1788. Frontera de Luján, 25 de noviembre de 1788. AGN, sala IX, legajo 13-8-17.

33. El análisis de las fuentes seleccionadas para este trabajo nos permite indagar en este tipo de intercambios, no obstante lo cual existieron una gran variedad de relaciones entre los grupos indígenas y los integrantes de las comitivas, tanto en las expediciones de aprovisionamiento de recursos económicos como en otras incursiones con objetivos diferentes.

34. Para un análisis de las interacciones entre los caciques y grupos étnicos con los funcionarios coloniales durante el siglo XVIII ver Carlón (2010) y Nacuzzi (2014b).

35. En cuanto a la escritura de los nombres de los caciques en plural, Alemano $(2015$, p. 48) apunta que "la propia enumeración sin solución de continuidad parece sugerir la existencia de linajes dentro de una misma familia étnica".

36. Diario de Manuel Pinazo sobre la expedición a Salinas del año 1786. Frontera de Luján, 28 de noviembre de 1786. AGN, sala IX, legajo 19-3-5.

37. Diario de Manuel Pinazo sobre la expedición de Salinas del año 1787. Frontera de Luján, 14 de diciembre 1787. AGN, sala IX, legajo 1-5-3. 
38. Diario de Manuel Pinazo sobre la expedición de Salinas del año 1788. Frontera de Luján, 25 de noviembre de 1788. AGN, sala IX, legajo 13-8-17.

39. Diario de Manuel Pinazo sobre la expedición de Salinas del año 1788. Frontera de Luján, 25 de noviembre de 1788. AGN, sala IX, legajo 13-8-17.

40. Blas Pedrosa había sido rescatado en la expedición de 1786 y en 1788 acompañó a Pinazo a Salinas, quizás en calidad de baqueano o de lenguaraz ya que conocía los territorios aledaños a las Salinas donde había permanecido cautivo diez años. Para un análisis de la trayectoria de este personaje ver Mandrini (2006).

41. Diario de Manuel Pinazo sobre la expedición a Salinas del año 1786. Frontera de Luján, 28 de noviembre de 1786. AGN, sala IX, legajo 19-3-5.

42. Para un análisis de la trayectoria de Francisca Bengolea ver Carbonari (2016).

43. Diario de Manuel Pinazo sobre la expedición de Salinas del año 1788. Frontera de Luján, 25 de noviembre de 1788. AGN, sala IX, legajo 13-8-17.

44. Diario de Manuel Pinazo sobre la expedición de Salinas del año 1787. Frontera de Luján, 14 de diciembre 1787. AGN, sala IX, legajo 1-5-3.

45. Diario de Manuel Pinazo sobre la expedición de Salinas del año 1787. Frontera de Luján, 14 de diciembre 1787. AGN, sala IX, legajo 1-5-3.

46. Diario de Manuel Pinazo sobre la expedición a Salinas del año 1786. Frontera de Luján, 28 de noviembre de 1786. AGN, sala IX, legajo 19-3-5.

47. Diario de Manuel Pinazo sobre la expedición de Salinas del año 1787. Frontera de Luján, 14 de diciembre 1787. AGN, sala IX, legajo 1-5-3.

48. Frontera de Luján, 8 de diciembre de 1778, Carta de Francisco Balcarce al señor Marqués de Loreto. AGN, IX, 1-6-3.

49. Borrador de carta al comandante de frontera. [Buenos Aires], 11 de diciembre de 1788, AGN, IX, 1-6-3.

50. Sobreescrito: 47 .

\section{ABSTRACTS}

Throughout the 18th century, salt was provided to the city of Buenos Aires through the organization of expeditions to the Salinas Grandes located in the current Atreucó department in the La Pampa province (current Republic of Argentina). Here we present transcripts of three diaries about the trips carried out in the years of 1786, 1787 and 1788 and a list of the captives rescued during these three voyages. These documentary sources produced by Manuel Pinazo, the commander, give us information about the everyday events in the field, the state of the roads, the availability of resources for the expeditioners, the interactions with caciques and indigenous groups as well as the diverse strategies implemented by the colonial agents, the troop and the other members of the expedition in order to move around places distant from the puestos fronterizos and close to the indigenous tolderías. In this writing we analyze the territorial dimension of the locations where the individuals that participated in these colonial expeditions interacted with the indigenous groups that approached them, highlighting the strategies of knowledge and control implemented by the different actors that circulated between the guardia de Luján and the Salinas Grandes. 
En el transcurso del siglo XVIII, la ciudad de Buenos Aires se abasteció de sal mediante la organización de expediciones hacia las Salinas Grandes localizadas en el actual departamento de Atreucó de la provincia de La Pampa (actual República Argentina). Presentamos aquí las transcripciones de tres diarios acerca de las incursiones realizadas en los años 1786, 1787 y 1788 y un listado de los cautivos rescatados durante los tres viajes. Estas fuentes documentales elaboradas por Manuel Pinazo, el comandante, nos permiten conocer los acontecimientos cotidianos en el terreno, del estado de los caminos, de la disponibilidad de recursos para los expedicionarios, de las interacciones con caciques y grupos indígenas así como las diversas estrategias implementadas por los funcionarios, la tropa y los demás integrantes de la expedición para transitar por lugares lejanos de los puestos fronterizos y cercanos a las tolderías indígenas. En este trabajo analizamos la dimensión territorial de aquellos parajes en los que interactuaban los sujetos que concurrían a las expediciones coloniales y los grupos indígenas que se acercaban a ellas, haciendo énfasis en las estrategias de conocimiento y control efectuadas por los distintos actores que circulaban entre la guardia de Luján y las Salinas Grandes.

\section{INDEX}

Keywords: Interethnic relations, expeditions, Salinas Grandes, itineraries

Palabras claves: Relaciones interétnicas, expediciones, Salinas Grandes, itinerarios

\section{AUTHOR}

\section{SABRINA LORENA VOLLWEILER}

Centro de Investigaciones Sociales (CIS) - Consejo Nacional de Investigaciones Científicas y Técnicas / Instituto de Desarrollo Económico y Social, Argentina Correo electrónico: vollweiler.sabrina@gmail.com 